\title{
Modelling and Fault Current Characterization of Superconducting Cable with High Temperature Superconducting Windings and Copper Stabilizer Layer
}

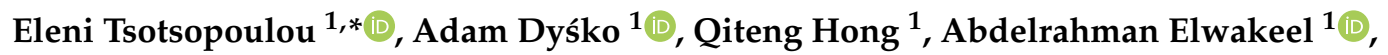 \\ Mariam Elshiekh ${ }^{1,2} \mathbb{}$, Weijia Yuan ${ }^{1}$, Campbell Booth ${ }^{1}$ and Dimitrios Tzelepis ${ }^{1}$ \\ 1 Department of Electronic and Electrical Engineering, University of Strathclyde, Glasgow G1 1XW, UK; \\ a.dysko@strath.ac.uk (A.D.); q.hong@strath.ac.uk (Q.H.); abdelrahman.elwakeel@strath.ac.uk (A.E.); \\ mariam.elshiekh@strath.ac.uk or mariam_elshaikh@f-eng.tanta.edu.eg (M.E.); \\ weijia.yuan@strath.ac.uk (W.Y.); campbell.d.booth@strath.ac.uk (C.B.); dimitrios.tzelepis@strath.ac.uk (D.T.) \\ 2 Department of Electronic and Electrical Engineering, Tanta University, Tanta 31512, Egypt \\ * Correspondence: eleni.tsotsopoulou.2018@uni.strath.ac.uk
}

Received: 22 November 2020; Accepted: 15 December 2020; Published: 16 December 2020

\begin{abstract}
With the high penetration of Renewable Energy Sources (RES) in power systems, the short-circuit levels have changed, creating the requirement for altering or upgrading the existing switchgear and protection schemes. In addition, the continuous increase in power (accounting both for generation and demand) has imposed, in some cases, the need for the reinforcement of existing power system assets such as feeders, transformers, and other substation equipment. To overcome these challenges, the development of superconducting devices with fault current limiting capabilities in power system applications has been proposed as a promising solution. This paper presents a power system fault analysis exercise in networks integrating Superconducting Cables (SCs). This studies utilized a validated model of SCs with second generation High Temperature Superconducting tapes (2G HTS tapes) and a parallel-connected copper stabilizer layer. The performance of the SCs during fault conditions has been tested in networks integrating both synchronous and converter-connected generation. During fault conditions, the utilization of the stabilizer layer provides an alternative path for transient fault currents, and therefore reduces heat generation and assists with the protection of the cable. The effect of the quenching phenomenon and the fault current limitation is analyzed from the perspective of both steady state and transient fault analysis. This paper also provides meaningful insights into SCs, with respect to fault current limiting features, and presents the challenges associated with the impact of SCs on power systems protection.
\end{abstract}

Keywords: superconducting cable; quench; high temperature; coppers stabilizer; superconducting tape; fault current limiting feature

\section{Introduction}

Transmission System Operators (TSOs) are responsible for the security of power grids and maintaining the balance between power generation and demand. However, new trends have emerged in power systems, pushing for a change in the way that networks are controlled, giving the TSOs plenty of new challenges to face in order to maintain the reliability and the security of power exchanges. The traditional power grids are gradually evolving towards power networks with high penetration of large-scale Renewable Energy Sources (RES) in both distribution and transmission level. In addition, more of the networks' equipment are reaching their capacity limits, while at the same time the 
utilities face several converging challenges caused by demand growth. All these factors bring about new challenges for future power systems, requiring the development of bulk power corridors as interconnections between different countries, and the upgrading of existing networks. Consequently, in order to avoid technologically, economically, and socially challenging solutions, such as building of new substations [1], there is a need for the investigation of new technologies which can overcome these restrictions and increase the electrical capacity and flexibility of the network.

In addition, the penetration of RES changes significantly the fault levels and the resulting fault current signatures. Such changes imply the need for upgrading the existing switchgear and protection systems. As a result, the utilization of Resistive Superconducting Fault Current Limiters (RSFCLs) has been proposed by [2-5] as a viable solution towards addressing the challenge of managing short circuit currents in power-dense systems. However, the RSFCLs are very expensive. Therefore, many researchers have been focused on the integration of fault current limiting features into other power system devices, in an attempt to take advantage of the unique features of the superconducting materials while fulfilling the cost requirements [6]. The studies presented in this paper promote that the utilization of SCs with a copper stabilizer layer connected in parallel. The main scope of this research is to study the fault current and voltage signatures resulted by the utilization of the SCs. Emphasis is given to the fault current limitation feature (as an extension to the cable's primary function as a lossless transmission media during steady state operation), in conjunction with the assessment of the potential benefits of the copper stabilizer layer during transient phenomena. The obtained results provide useful information regarding the fault analysis of future power grids integrating SCs and high amounts of RES, which can be considered as a prerequisite step for designing effective protection schemes.

\subsection{Characteristics of Superconducting Cables}

In recent years, the deployment of Superconducting Cables (SCs) in power system applications has become widely accepted due to their unique characteristics. Several prototype projects have been carried out worldwide which proposed the utilization of different configurations of SCs as a viable solution for bulk power transmission [7-12].

Compared to conventional cables, SCs are characterized by a plethora of technically-attractive features, such as higher current-carrying capability [13], higher power transfer at lower operating voltages and over longer distances [1,14], lower losses due to their lower resistance compared to that of overhead transmission lines [15], and more compact size due to their high current density. Therefore, the installation of SCs is considered a promising solution against congestion, especially in high power density areas such as metropolitan meshed networks. Furthermore, their fundamental property of transferring power over long distances, at low voltage levels, renders them the most effective way to interconnect renewable energy sources, such as offshore wind farms, to the power grid.

The superconducting behavior appears after cooling down the superconductor below a characteristic temperature, known as critical temperature $T_{C}$, which has a specific value for each superconducting material [16-19]. The maximum value of the current that can be conducted through the superconductor without encountering increase in the resistance value is called critical current $I_{C}$. However, superconductors lose their superconductivity if the magnetic field reaches its critical value $H_{C}$ or in case the temperature increases beyond $T_{C}$. This phenomenon is called quench. These remarkable physical properties of SCs make them capable of conducting currents with approximately zero electrical resistance during steady state, while their variable resistance, which is dependent on the load current, in conjunction with the introduction of a high resistive layer into the superconducting wire, such as copper, result in fault current limitation in short-circuit situations. The contribution of SCs to fault current limitation is determined by the design. 
1.2. Challenges Associated with the High Temperature Superconducting Cables Installation and the Superconducting Cables (SCs)

The discovery of HTS materials created the opportunity of applying the superconductivity principles to electric power devices such as, superconducting machines and SCs. The major advantage of the HTS materials is that their high critical temperature values, $T_{C}$, are attainable using liquid nitrogen, $L N_{2}$, as coolant with a boiling temperature of $77 \mathrm{~K}$ [20-22]. For the presented case studies, the Yttrium Barium Copper Oxide (YBCO) material has been chosen with $T_{C(Y B C O)}=93 \mathrm{~K}$, which belongs to the 2nd generation of HTS tapes (2G), as its transition from the superconducting state to normal state lasts for a few milliseconds, which makes it attractive considering the fault current limitation capability [8].

In addition, one of the most challenging tasks to be achieved is the connection between HTS cables and existing conventional circuits [23-25]. It is important to understand that the direction and the magnitude of power flows could be affected by the installation of HTS cables, due to their low impedance. During steady state conditions, HTS cables operate at the superconducting state, presenting the current path with approximately zero resistance and as a consequent, attracting naturally the power flow. These significant changes in the current distribution and the rearrangements of power flows must be considered in order to maintain power system stability.

Furthermore, the installation of HTS power cables impacts on the short-circuit level of the power system. The changes in the short-circuit level, and as a consequence the changes in the fault currents, affect the performance and design of power system protection schemes. The incorporation of the copper parallel layer and fault current limiting features in SCs cables have made them increasingly appealing for power system applications [26,27]. In steady state condition SCs transmit bulk power with low losses. Under fault conditions, when the fault current flowing through the HTS tapes exceeds the critical current $I_{C}$, the superconducting tapes will automatically quench and switch to normal resistive state. As the fault current increases, the resistance and the temperature of the cable increase as well, as interdependent variables. The transition from the superconducting state to the normal resistive state during short circuit conditions can occur within milliseconds (i.e., within a single AC cycle). Consequently, the integration of the fault current limiting feature into the HTS cable can limit the short-circuit current to a certain point, helping towards protecting the system [27]. This property of the SCs creates new challenges for the power system protection, as the calculation of the expected short-circuit level must be conducted in accordance with the variable resistance of the installed SCs.

The paper is organized as follows: Section 2 presents the detailed mathematical development of the utilized cable based on well-known equations which explain the behavior of superconductors. The model is developed using Matlab and Simulink software and is applied to a power system which contains wind farms and synchronous generators. In Section 3, different fault scenarios are carried out which aim to investigate the cable performance during transients and verify the practical feasibility of the proposed SCs model.

\section{Modelling of SCs with 2G HTS Wires}

Various numerical models of HTS cables have been recently proposed, which use the Finite Element Method (FEM) or finite-difference time-domain (FDTD) analysis to understand the non-linear electromagnetic properties of the superconductors [28-31]. The investigation of the electromagnetic and thermal properties of the HTS cables is an effective way to predict and optimize the cable performance under different operating conditions. However, for power system studies such as fault analysis, the performance of the numerical models using FEM and FDTD is compromised due to the computational complexity [30]. Thus, a simplified time-dependent model of a multilayer HTS cable will be analyzed in this research, providing a solid foundation for the utilization of SCs in power system applications. 


\subsection{Configuration and Design Specifications}

Several design topologies of SCs have been developed to minimize the capital and operating costs. The different configurations can be classified based on the superconducting layer layout for each phase and the voltage level. One design, known as triaxial configuration involves three different phases attached onto a single former, contained in a single cryostat [1] as shown in Figure 1. The three phases are separated by a dielectric layer which provides electric insulation. The circulating liquid nitrogen flows between the copper screen and the inner cryostat wall to cool down the entire cable to a temperature range of 65-77 K [31]. This configuration offers higher carrying current capacity, and has the lowest inductance compared to other cable designs. Regarding the position of the insulation layer, SCs can be separated into two categories, namely the warm dielectric (WD) and the cold dielectric (CD), with the latter to be the most preferred design due to low losses and higher current capacity [32]. In this paper, a CD triaxial SCs with YBCO wires has been modelled. The detailed structure of the SCs tape is demonstrated in Figure 2.

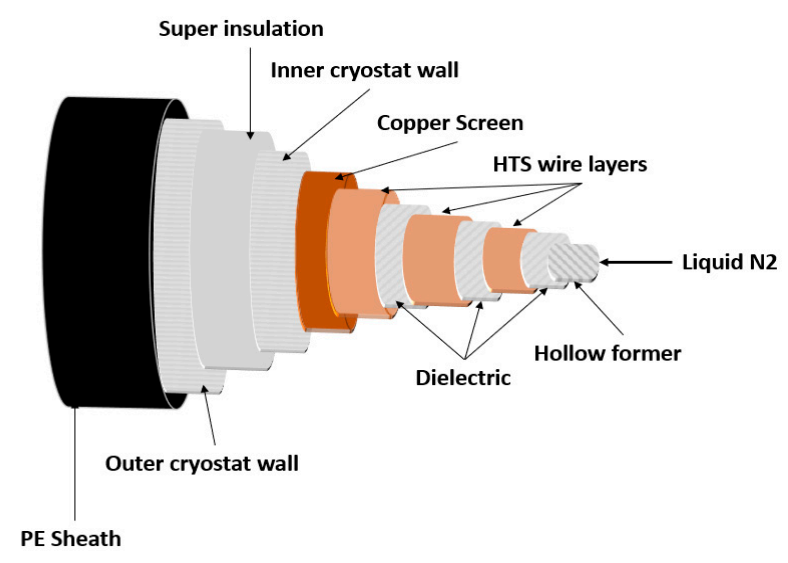

Figure 1. Configuration of triaxial SCs cable.

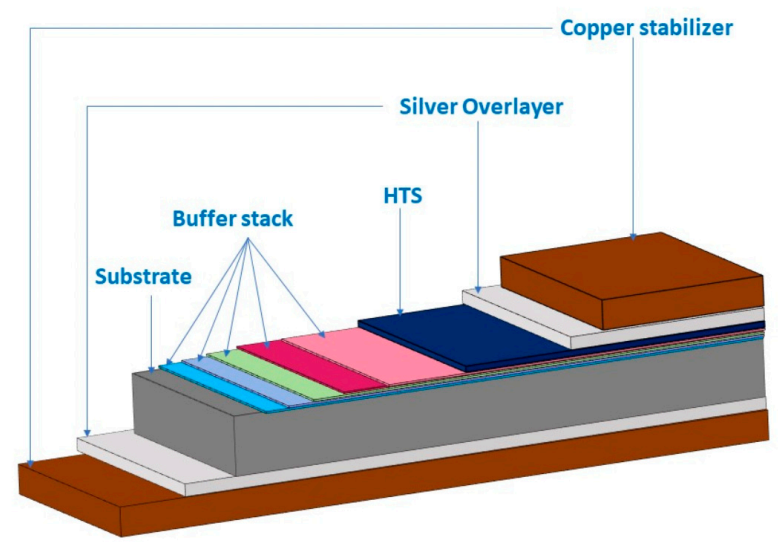

Figure 2. Configuration of SCs tape.

The typical structure of the YBCO tape consists of the YBCO layer, the copper stabilizer layer, the silver stabilizer layer, the Hastelloy substrate and the buffer layer which is placed between the substrate and the YBCO layer [33]. The YBCO layer, which is the only layer responsible for conducting the load current during the steady state operation, is manufactured as a film with very small thickness, protected by copper stabilizer layers on both sides. In the superconducting wire, a stabilizer layer (such as copper) is connected in parallel with the HTS layer to maintain stability, reduce the heat generation and the temperature during high current faults, and protect the cable from thermal-induced damage. This technique has been introduced and adopted by major manufacturers [34-37]. For the 
fault analysis, due to the parallel structure of the layers, the total fault current flowing through each phase must meet Equation (1),

$$
I_{\text {total }}=I_{H T S}+I_{\text {Copper }}
$$

where $I_{\text {total }}$ is the total current, $I_{\text {HTS }}$ is the current in YBCO layer and $I_{\text {Copper }}$ is the current flowing in the copper layer. Specifically, as it is illustrated in Figure 3, in steady state, during which the HTS tapes are in the superconducting state, the load current only flows through the HTS layer (i.e., as presented by Equation (2)), due to its very low impedance compared to that of the copper stabilizer,

$$
I_{\text {total }}=I_{H T S}
$$

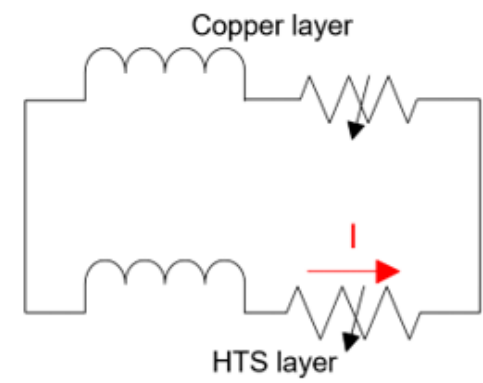

a)

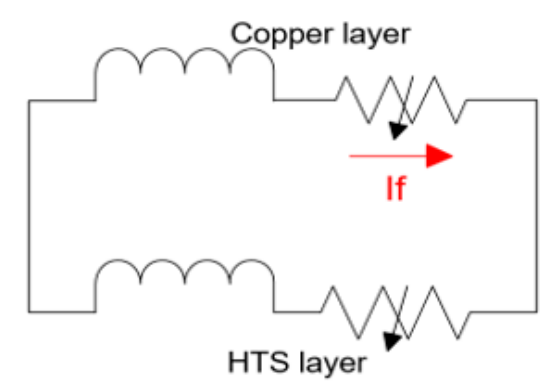

b)

Figure 3. Operation of HTS cable during (a) steady state (b) fault.

In this case, during the steady state, the $I_{\text {Copper }}$ is approximately zero.

In transient conditions, once the fault current exceeds the value of the critical current $I_{C}$ the HTS tapes quench and their resistivity increases exponentially. Furthermore, the temperature of the HTS tapes is affected by the generated heat. The temperature increases gradually and exceeds the value of the critical temperature $T_{C}$, indicating the transition to the normal state. Once the HTS tapes enter the normal state, the variable resistance, which is a function of the current density $J$ and the temperature $T$, reaches values which are much higher than that of the copper layer. Hence, the transient current is diverted into the copper stabilizer layer, as expressed in Equation (3), which acts as a by-pass circuit. Thus, the effect of the stabilizer layer is important for the transient studies,

$$
I_{\text {total }}=I_{\text {Copper }}
$$

where $I_{\text {Copper }}$ is the diverted fault current, flowing through the stabilizer layers, while a very small current (approximately zero) flowing through the HTS layers.

Based on the analysis presented above and according to the study conducted in [37], the boundary of the critical current $I_{C}$ determines whether or not the superconducting tape quenches. Thus, exceeding the threshold of $I_{C}$ can be considered as the impelling factor that leads to quench, while the threshold of the critical temperature $T_{C}$ determines if the superconductor will enter the highly resistive normal state. Therefore, it can be defined as a criterion for the degree of quenching. To further study the performance of the integrated HTS cables, it is of major importance to investigate in more detail the transition period from the superconducting to the normal state. To study the quenching process, special focus should be given to the current distribution among the layers and the resistance variations with respect to the accumulated heat and the current amplitude. In the following part, the proper design of a simplified model of multilayer HTS power cable will be presented. 


\subsection{Development of SCs Model}

\subsubsection{Equivalent Circuit}

Each phase of the cable consists of (i) several HTS tapes connected in parallel, in order to cope with the large operating current, and (ii) two copper-stabilizer layers connected in parallel with the HTS layer. The rest of the cable layers shown in Figure 2 have been neglected for simplicity reasons as the increase of the temperature mainly affects the resistance of the HTS and the copper stabilizer layer. The number of the tapes and the layers have been selected after taking into consideration the value of the designed critical current $I_{C}$, while the geometric characteristics of the tapes have been determined based on the maximum quenching voltage [38]. In particular, the rated current $I_{\text {rated }}$ during the steady state operation has been considered equal to $80 \%$ of the critical current $I_{C}$ [39]. Therefore, the number of tapes can be calculated by the following equation,

$$
I_{\text {rated }}=0.8 \cdot I_{C_{-} \text {initial_per_tape }} \cdot n
$$

where $I_{C_{-} \text {initial_per_tape, }}$ corresponds to the initial value of the critical current for each YBCO tape, and has been estimated based on validated manufacturers' data presented in [8], where $n$ is the number of tapes.

The equivalent impedance of each phase is dependent on the current distribution among the HTS and the copper layers. Figure 4. shows the equivalent circuit of the three phase triaxial SCs. The resistance of the HTS layers is introduced as a variable resistance which represents the quench phenomenon with an initial value of approximately zero. The PI section model has also been used, in order to implement the self- and mutual-inductances and the capacitance of the cable. The resistance of the copper stabilizer has been modelled as a variable resistor. Once the current increases to higher than the critical value $I_{C}$, the HTS tapes resistance starts to increase and the current flows in both the superconducting and the copper layers. During this process, heat is generated in the tape resulting in a dramatic temperature rise. Once the temperature exceeds $T_{C}$, the cable reaches the normal state mode and the current flows through the copper layer.

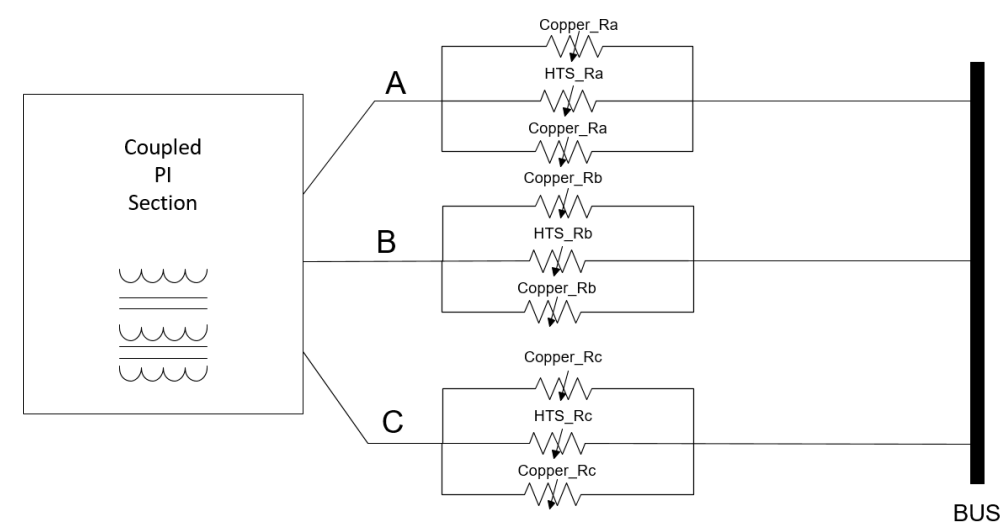

Figure 4. Equivalent electrical circuit of the modeled cable.

\subsubsection{Modelling Methodology}

The following Section presents the detailed equations that have been used for the SCs development and the subprocess that has been followed to calculate the resistance of each layer. The modelling method followed is based on the equations proposed by the authors in [40], in which the modelling of transformers with superconducting windings is presented. To describe the HTS and copper layers, the operation of the multilayer SCs has been divided into three modes (referred as three distinct stages for simplicity) with respect to the current distribution and the values of the equivalent resistance. 
Stage 1 refers to the superconducting mode, where the applied current is lower than the critical current $I_{C}$ and the temperature is considered to be below the critical temperature $T_{C}$,

$$
\begin{gathered}
I_{\text {applied }}<I_{C} \\
T=T_{\text {operating }}
\end{gathered}
$$

where $T_{\text {operating }}$ is the operating temperature of $70 \mathrm{~K}$.

Stage 2 refers to the flux flow mode, when the quench starts, and is determined by the following boundary conditions:

$$
\begin{gathered}
I_{\text {applied }}>I_{C} \\
T<T_{C}
\end{gathered}
$$

At this stage the HTS tapes start to quench and their resistivity increases sharply as a function of the current density $J_{C}$ and the accumulated heat.

At the final mode, stage 3, which is described by the boundary conditions (9) and (10), the HTS layer completely loses its superconductivity and enters normal state.

$$
\begin{gathered}
I_{\text {applied }}>I_{C} \\
T>T_{C}
\end{gathered}
$$

The main parameters that affect the resistance value and the operation mode of the HTS tapes-layers are the critical current density $J_{C}$, and the critical temperature $T_{C}$ [7]. The relationship between the temperature $\mathrm{T}$, the current density $J_{C}$ and the critical current $I_{C}$ is given by the following equations,

$$
\begin{gathered}
J_{C}(\mathrm{~T})=\left\{\begin{array}{c}
J_{C 0} \cdot\left(\frac{\left(T_{C}-T(t)\right)^{a}}{\left(T_{C}-T_{0}\right)^{a}}\right. \\
0>T_{C}
\end{array}\right. \\
J_{C 0}=\frac{I_{C_{-} \text {initial }}}{s_{H T S}} \\
I_{C_{\text {_initial }}}=267 \cdot \mathrm{n} \\
s_{\text {HTS }}=w_{\text {HTS }} \cdot t_{H T S} \cdot \mathrm{n}
\end{gathered}
$$

where $J_{C 0}$ is the critical current density $\left(A / \mathrm{m}^{2}\right)$ at the initial operating temperature $T_{0}=70 \mathrm{~K}$; $T_{C}=92 \mathrm{~K}$ is the critical temperature of the HTS superconducting tape; the density exponent $a$ is $1.5 ; I_{C_{-} \text {initial }}$ corresponds to the initial value of the critical current and $s_{H T S}$ is the cross section area of the superconductor; $w_{H T S}$ is the width of the HTS material and $t_{H T S}$ is the thickness of the HTS material and $n$ is the number of tapes. As can be seen from Equations (11)-(13), the value of the critical current density $J_{C}(T)$, and by extent the value of the critical current $I_{C_{-} \text {initial }}$, decreases drastically as the temperature $T(t)$ rises. The temperature dependence on the critical current density is known in literature as 'critical current density degradation' [41]. The effect of the resulting degradation must be taken into consideration for the design of large-current-capacity AC SCs and their cooling systems.

To better understand the operation of the HTS cable it is crucial to estimate the resistance of the HTS and the copper stabilizer layers and the equivalent resistance of the SCs at every stage. Initially, at stage 1 , the HTS tape is in a superconducting state. The resistivity of the HTS tape is $\rho_{0}=0(\Omega \cdot \mathrm{m})$ and therefore its total resistance equals approximately zero. The copper stabilizer resistance has been considered constant and the total equivalent resistance of the cable is equal to the HTS layer resistance, as the main current flows through it only. At stage 2, when the applied current exceeds the value of 
the critical current, the resistivity of the HTS tape increases exponentially as a function of the current density and the temperature, according to Equation (15),

$$
\rho_{H T S}=\frac{E_{C}}{J_{C}(T)} \cdot\left(\frac{J}{J_{C}(T)}\right)^{N-1}, I>I_{C}, T<T_{C}
$$

where $E_{C}=1 \mu \mathrm{V} / \mathrm{cm}$ is the critical electric field; the coefficient $\mathrm{N}$ has been selected to be 25 , while the YBCO tapes should be within the range of 21 to 30 [42]. The copper stabilizer resistance corresponds to a constant value, similar to that of stage 1 . This approximation can be confirmed by the small variation of copper resistivity with the temperature rise at this stage. The total resistance of the superconductor is obtained by the equation for equivalent resistance of parallel electrical circuits,

$$
R_{S C}=\frac{R_{H T S} \cdot R_{C u}}{R_{H T S}+R_{C u}}
$$

where $R_{S C}$ is the total resistance of the SC during stage 2.

When $T>T_{C}$, stage 3 has been initiated, which corresponds to the normal resistive mode. The HTS layer-tape resistance reaches values much larger than the copper stabilizer resistance. For modelling purposes, a maximum limit has been set for the HTS resistance value at stage 3 . However, in this case the resistivity $(\Omega \cdot \mathrm{m})$ of the copper changes with respect to temperature rise and is determined by Equation (17). The maximum value that copper resistivity can reach is calculated for $T=250 \mathrm{~K}$, which has been selected as the upper temperature limit [43].

$$
\rho_{C u}=(0.0084 \cdot T-0.4603) \cdot 10^{-8}, 250 \mathrm{~K} \geq T>T_{C}
$$

During the normal mode, the equivalent resistance of the SFCLC is affected solely by the value of the copper stabilizer resistance, as the transient current is diverted into the copper layers.

\subsubsection{Thermal Transfer Analysis during the Quenching}

Superconducting tapes are immersed in liquid nitrogen $L N_{2}$, which is used as a refrigerant for cooling the SCs below a certain temperature. When the resistance of the HTS tapes is zero, (stage 1) the amount of the power dissipated is not considered significant. When a fault occurs, the resistance increases, and heat is generated by the superconductor. The generated heat increases the superconductor temperature and part of it is absorbed by the $L N_{2}$ circulation system (the heat transfer with the external environment has been neglected). The power dissipated is a function of the fault current and can be calculated by Equation (18),

$$
P_{\text {diss }}=i(t)^{2} \cdot R_{S C}
$$

where $t$ is time and $R_{S C}$ is the equivalent resistance of the superconductor.

The cooling power that can be removed by the $L N_{2}$ cooler is given by Equation (19),

$$
P_{\text {cooling }}=h \cdot A \cdot(T(t)-70)
$$

where $T(t)$ is the temperature; $A$ is the total area that is covered by the cooler; $h$ is the heat transfer coefficient. The heat transfer coefficient is a function of the temperature and considered as the major factor which determines the cooling system effectiveness and the cable recovery, representing the heat transfer process between the superconducting tapes and the $L N_{2}$. Equations (20)-(23) below present the calculation of $h$ based on the temperature variation [44].

$$
\begin{gathered}
h=125+0.069 \cdot \Delta T, 56.3 \leq \Delta T \leq 214 \\
h=12292.13-709.32 \cdot \Delta T+14.735 \cdot \Delta T^{2}, 18.94 \leq \Delta T \leq 56.3
\end{gathered}
$$




$$
\begin{gathered}
h=82.74-131.22 \cdot \Delta T+37.64 \cdot \Delta T^{2}, 4 \leq \Delta T \leq 18.94 \\
h=21.945 \cdot \Delta T, 0 \leq \Delta T \leq 4
\end{gathered}
$$

If Equation (19) is subtracted from Equation (18) then the net power $P_{S C}$ can be calculated. Equation (24) is the thermal equilibrium equation which gives the part of the dissipated power which leads to temperature rise in the superconductor during the quenching process.

$$
P_{S C}(t)=P_{\text {diss }}(t)-P_{\text {cooling }}(t)
$$

Finally, Equation (25) gives the temperature $T(t)$ of the superconducting tapes at each iteration step,

$$
T(t)=T_{0}+\frac{1}{C_{p}} \cdot \int_{0}^{t} P_{S C}(t) d t
$$

where $T_{0}$ is the initial temperature of the HTS materials and $C_{p}(\mathrm{~J} / \mathrm{K})$ is the heat capacity.

For stage 2, when the quenching starts, the current starts to flow through the copper layer. However, as the temperature rise is not very high at this stage, the copper heat capacity variation with the temperature is neglected. The heat capacity of the YBCO material can be calculated by Equation (26) and the volume of the cable by Equation (27),

$$
\begin{aligned}
& C_{P}=2 \cdot T \cdot d \cdot v \\
& v=l \cdot t h \cdot w \cdot n
\end{aligned}
$$

where $d$ is the density of the material, $T$ is the temperature, $v$ is volume and $l$ is length; th is the thickness and $w$ is the width and $n$ is the number of tapes. At stage 3, when the resistance of the HTS tapes-layer has reached very high values due to the increased temperature, the fault current flows through the copper layers. In this case the heat capacity in Equation (28) is substituted by the total heat capacity of the superconductor Equation (29) gives the heat capacity of the copper layer,

$$
\begin{aligned}
& C_{P}=C_{P H T S}+C_{C u} \\
& C_{P C u}=C_{C u} \cdot d_{C u} \cdot v
\end{aligned}
$$

\begin{tabular}{|c|c|c|c|}
\hline \multicolumn{4}{|c|}{ Quenching Process } \\
\hline Parameters & 1. Supercondu-Cting State & 2. Quenching: Flux Flow State & 3. Quenching: Normal State \\
\hline $\begin{array}{c}\text { Critical } \\
\text { current/temperature }\end{array}$ & $I_{\text {applied }}<I_{C}$ & $I_{\text {fault }}>I_{C}, T<T_{C}$ & $I_{\text {fault }}>I_{C} \cdot T>T_{C}$ \\
\hline $\begin{array}{l}\text { Resistivity of } \\
\text { HTS layer } \rho_{H T S}\end{array}$ & $\rho_{\text {HTS }}=0$ & $\rho_{H T S}=\frac{E_{C}}{J_{C}(T)} \cdot\left(\frac{J}{J_{C}(T)}\right)^{N-1}$ & $\rho_{H T S}=$ max_value \\
\hline $\begin{array}{l}\text { Resistivity of Copper } \\
\text { layer } \rho_{C u}\end{array}$ & $\rho_{\mathrm{Cu}}=\rho_{\text {Constant }}$ & $\rho_{\mathrm{Cu}}=\rho_{\text {Constant }}$ & $\rho_{C u}=(0.0084 \cdot T-0.4603) \cdot 10^{-8}$ \\
\hline Current distribution & $I_{\text {applied }}>I_{H T S}$ & $I_{H T S}>I_{C u}$ & $I_{C u}>I_{H T S}, I_{\text {fault }}=I_{C u}$ \\
\hline
\end{tabular}

where $C_{C u}$ is the heat capacity of the copper and $d_{C u}$ is the density of the copper.

The classification of the quenching process and the corresponding characteristics of each stage are listed in Table 1.

Table 1. Quenching characteristics.

Matlab has been used to model Equations (11)-(29) in order to compute the resistance values of the HTS tapes $R_{H T S}$, the copper stabilizer $R_{C u}$, and the variation of the temperature $\Delta T$ of the superconductor. The calculation process is shown in Figure 5. $T_{0, l}, I_{C_{-} \text {initial }}, J_{C_{\text {initial }}}$ are the initial values of 
the operating temperature, critical current and critical current density for the first iteration, respectively. Once the $I_{r m s}$ gives a value of current density $J_{i}$, which exceeds the critical value $J_{C}$, the HTS tapes start to quench. During the quenching process the values of $I_{r m s} P_{\text {diss }}, P_{\text {cooling }}, P_{S C}$, and $T_{i+1}$ are updated in each time step, $T_{\text {step }}$. The calculation process terminates once the $T_{i+1}, R_{H T S}$, and $R_{C u}$ reach their maximum values, indicating that superconductor has entered into normal state.

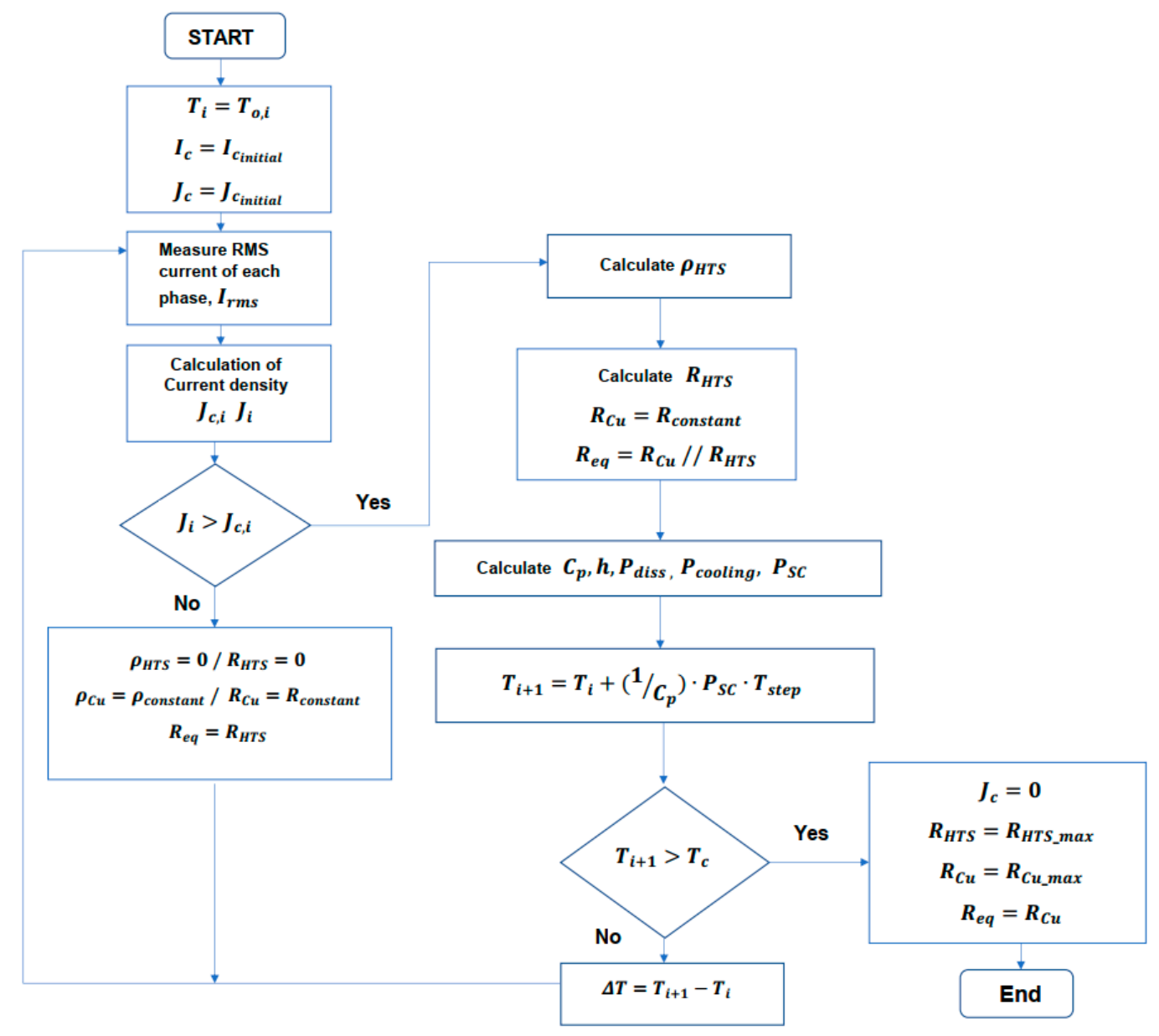

Figure 5. Flowchart corresponding to the calculation process for the resistance values of the HTS tapes $R_{H T S}$, the copper stabilizer $R_{C u}$, the equivalent $R_{e q}$, and the variation of the temperature $\Delta T$ of the superconductor.

\section{Simulation Results}

In this Section the model development is completed by integrating a lumped model of a $5 \mathrm{~km}$ long SCs into a simulated power system which contains converter-connected generators and a synchronous generator (SG). The fault analysis is carried out, analyzing the stages of the quenching process, and the corresponding plots of the fault current signatures, resistance values, and temperature have been obtained. For the purpose of the simulation-based fault analysis, the system under test (as shown in Figure 6) has been built in Matlab and Simulink shows the components of the tested system. Table 2 presents the main components of the power system.

The network consists of an equivalent voltage source connected at Bus 1 with a nominal voltage of $275 \mathrm{kV}$, which represent the equivalent connected transmission system. Two different generation units accounting for (i) a wind farm connected via Voltage Source Converter (VSC) and (ii) a Synchronous Generator (SG) are connected at Bus 11. The SG has been modelled as a standard salient pole synchronous machine with an automatic voltage regulator (AVR) and a power system stabilizer. The wind farm consists of 100 variable speed wind turbines, which consist of permanent magnet SGs 
connected via VSC and operate under a Direct Quadrature Current Injection (DQCI) control algorithm. The $132 \mathrm{kV} / 10 \mathrm{~km}$ transmission lines transfer power to $(132 \mathrm{kV} / 33 \mathrm{kV})$ transformers. The $33 \mathrm{kV}$ triaxial SCs connects Bus 7 and Bus 11, and due to its high-power density it is capable of transfering power up to 202 MVA. For the steady state, the resistance of the HTS tapes has been considered approximately zero while the positive and zero sequence inductance and capacitance have been obtained by [23]. Regarding the final stage of the quenching process, known as normal state, for simulation purposes, a maximum value has been set for both the HTS and copper stabilizer layers. The idea behind this assumption was to model the change of HTS and copper layer resistance according to the current and temperature changes and examine the current distribution among the different layers during the quench phenomenon. These assumptions can be considered reasonable as the HTS layers become highly resistive during the fault which results in the flow of short-circuit current through the stabilizer. Therefore, for the normal state, a high resistance value has been selected for the HTS layer, based on the studies conducted in [40]. The maximum resistivity of the copper stabilizer layer has been calculated by using Equation (17) for a temperature $T=250 \mathrm{~K}$. The corresponding parameters and the specifications of the proposed HTS cable are listed in Tables 3 and 4.

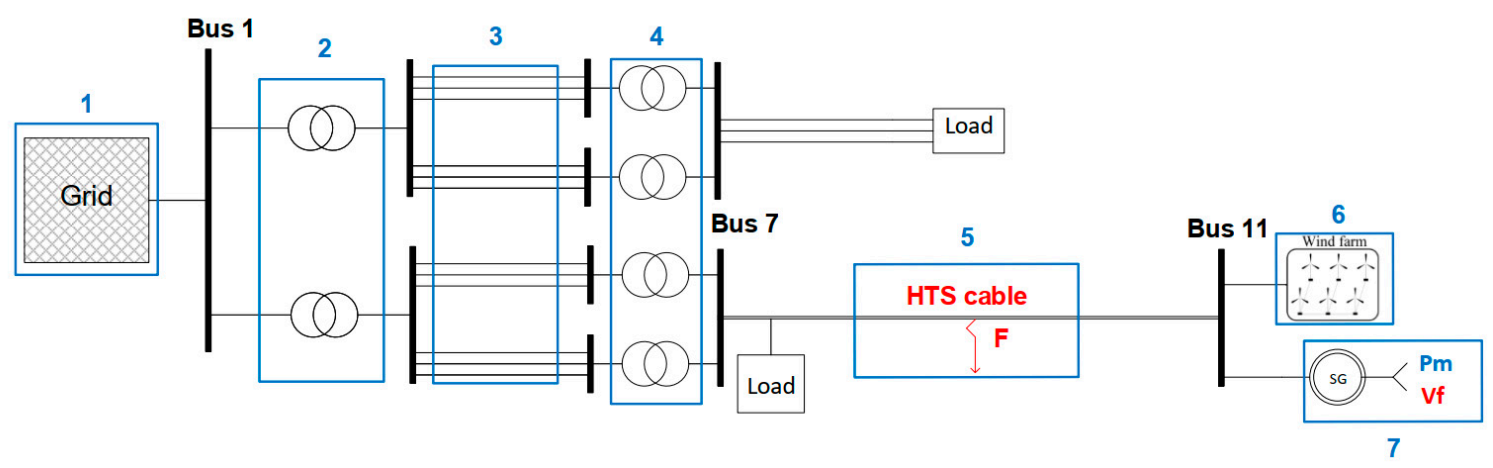

Figure 6. Case study test network.

Table 2. Components of the tested system.

\begin{tabular}{cc}
\hline Number & Components \\
\hline 1 & Grid \\
2 & Transformers $275 \mathrm{kV} / 132 \mathrm{kV}, 150 \mathrm{MVA}$ \\
3 & $10 \mathrm{~km}$ transmission lines \\
4 & Transformers $132 \mathrm{kV} / 33 \mathrm{kV}$ \\
5 & $5 \mathrm{~km} \mathrm{SC}$ \\
6 & Converter-interfaced generator (Wind farm) \\
7 & Synchronous generator \\
\hline
\end{tabular}

Table 3. SC Parameters.

\begin{tabular}{ccc}
\hline \multicolumn{3}{c}{ Cable Parameters } \\
\hline Parameters & Symbol & Value \\
\hline Cable length & $l$ & $5 \mathrm{~km}$ \\
No. of YBCO tapes & $n$ & 15 \\
Critical current & $I_{C}$ & $256 \cdot n$ \\
Critical temperature & $T_{C}$ & $92 \mathrm{~K}$ \\
Width of YBCO tape & $\mathrm{w}$ & $0.004 \mathrm{~m}$ \\
Thickness of YBCO tape & $t_{H T S}$ & $1 \mu \mathrm{m}$ \\
Thickness of copper tape & $t_{C u}$ & $40 \mu \mathrm{m}$ \\
Density of YBCO tape & $d_{H T S}$ & $5900\left(\mathrm{~kg} / \mathrm{m}^{3}\right)$ \\
Density of copper tape & $d_{C u}$ & $8940\left(\mathrm{~kg} / \mathrm{m}^{3}\right)$ \\
\hline
\end{tabular}


Table 4. Specifications of $33 \mathrm{kV} \mathrm{SC}$.

\begin{tabular}{ccc}
\hline \multicolumn{3}{c}{ Cable Specifications } \\
\hline Parameters & Symbol & Value \\
\hline Rated Voltage & $V$ & $33 \mathrm{kV}$ \\
Operating Temperature & $T$ & $70 \mathrm{~K}$ \\
Rated Capacity & $S$ & $202 \mathrm{MVA}$ \\
\hline
\end{tabular}

In the following part, systematic iterative simulations have been performed, which include (i) 3-Phase-to-ground faults at two different fault locations, (ii) a Phase-to-Phase-to-ground fault and (iii) a Phase-to-ground fault. In all cases the faults initiate at $t=5.06 \mathrm{~s}$ and last for $120 \mathrm{~ms}$. To obtain a high-fidelity insight of the transient phenomena of SCs, a sampling frequency of $f=2 \mathrm{MHz}$ has been used (accounting for simulations and records).

\subsection{Fault Analysis of the SCs}

Initially, a 3-Phase-to-ground fault with fault resistance $R_{f}=0.01 \Omega$ was triggered at $50 \%$ of the HTS cable's length at $t=5.06 \mathrm{~s}$, and it was cleared after $120 \mathrm{~ms}$. Figure 7 shows the stages of the quenching process, Figure 8a illustrates the fault current signatures contributed by the wind farm and the SG at Bus 11, while Figure 8b presents the corresponding voltage signatures. The resulting fault current distribution among the different layers of the three phases is shown in Figure $8 \mathrm{c}-\mathrm{h}$. At the superconducting state (stage 1) and the flux flow state, which is a moderately resistive state, the current flows through the HTS layers, presenting high peaks due to the low resistance of the superconductor when the fault occurs. However, as the fault current exceeds the critical value $I_{C}$ in the flux flow mode (stage 2), the temperature rises continuously and the value of the resistance of the superconductor increases rapidly to very high values, reaching the normal state (stage 3 ). Therefore, as it can be seen from Figure $8 \mathrm{~d}, \mathrm{f}, \mathrm{h}$, the main current has been diverted to the copper stabilizer layers, indicating that the normal state has been reached, while the HTS layers conduct approximately zero current. Figures 9 and 10 illustrate the changes in the resistance values and the temperature rise, respectively. Initially, the temperature is $70 \mathrm{~K}$ for the three phases and the equivalent resistance of the superconductor is approximately zero. Once the temperature exceeds $92 \mathrm{~K}$, which is the critical value, at $t=5.064 \mathrm{~s}$, the HTS tapes enter the normal state and their resistance starts to increase rapidly. For stage 2, the equivalent resistance of the superconductor is calculated based on Equation (16). The current distribution starts to change, and the fault current is diverted to the stabilizer layers. Subsequently, in the normal state (stage 3 ) the equivalent resistivity is equal to the maximum resistivity of the copper stabilizer layer obtained by Equation (17). Therefore, the proposed design has achieved the current sharing between the HTS and stabilizer layers, aiming to improve the performance of the cable and self-protecting it from being destroyed.
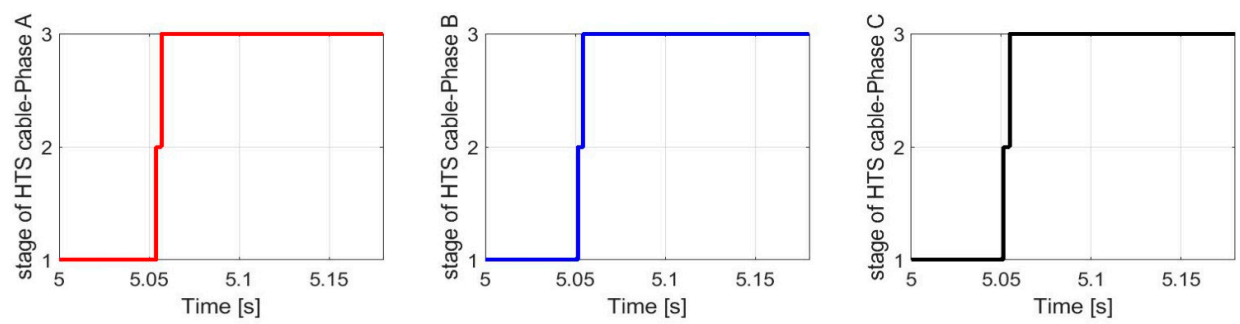

Figure 7. Stages of quenching process for phase A, B, and C for 3-Phase-to-ground solid fault at 50\% of cable's length.

As discussed earlier, the installation of the SCs impacts the magnitude of fault currents. Indeed, from the fault current waveforms plotted in Figure 8, at the time of the fault event at $t=5.06 \mathrm{~s}$, the highest first current peak is approximately $15 \mathrm{kA}$. As the value of the layers' resistance increases 
immediately, the magnitude of the fault currents decreases. Specifically, at $t=5.064 \mathrm{~s}$, when the values of resistances and the temperature reach high values, the fault current starts flowing through the stabilizer layers, presenting peaks of approximately $5.5 \mathrm{kA}$. During the current elimination within the first fault cycle, some peaks are presented at the 3-Phase fault voltages. Moreover, it is noticeable that after $t=5.069 \mathrm{~s}$ and before the fault clearance at $t=5.18 \mathrm{~s}$, the magnitude of fault currents at Bus 11 are limited and the phase voltages show higher magnitudes compared to steady state. This is interpreted based on the large equivalent resistance inserted by the SCs. Hence, it is evident that SCs provide effective limitation of fault currents in systems containing SGs and converter-interfaced generators. Such fault current limiting capability seems to be an interesting feature in regards towards protecting networks with varying short-circuit levels. Furthermore, the high voltage magnitudes during transient conditions raises new challenges for the voltage-assisted protection schemes. Normally, during the fault events, the voltage magnitude is anticipated to be reduced. However, in this case, when the fault occurs at $t=5.06 \mathrm{~s}$, the 3-Phase voltages decrease for few milliseconds, but when the equivalent resistance of the superconductor increases, the fault current decreases, while the 3-Phase voltages present high peaks. The introduction of high equivalent resistance leads to voltage spikes across the superconductor. The faults at the SCs can be considered as high impedance faults in nature, jeopardizing the operation of the existing protection schemes.
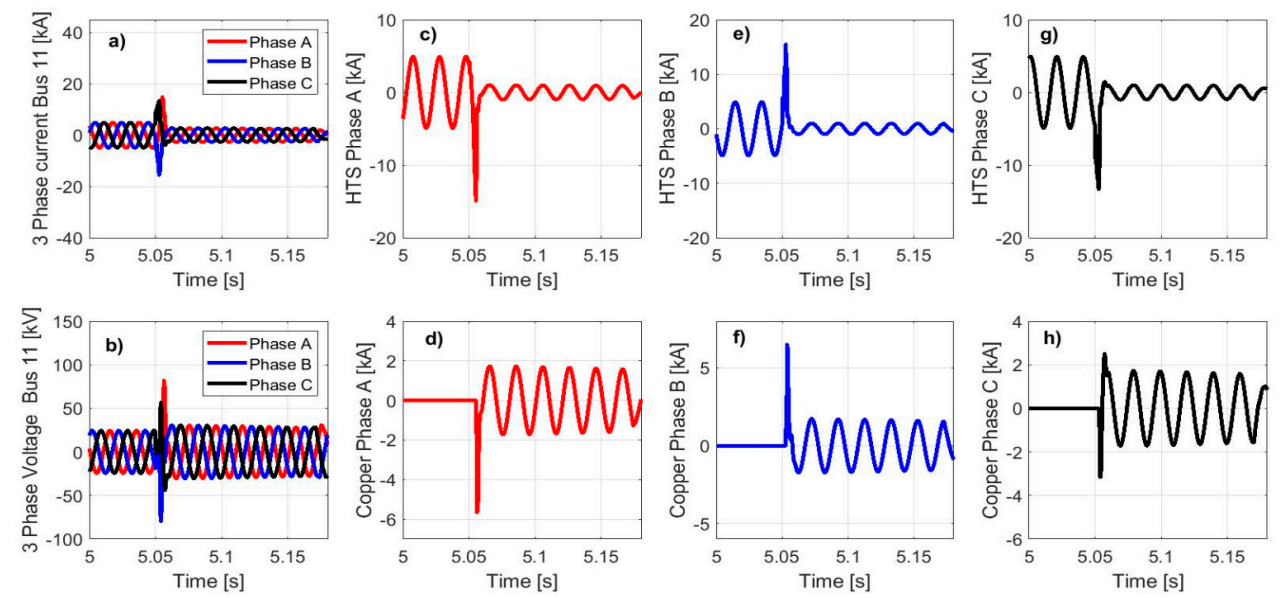

Figure 8. Fault current and voltage signatures for 3-Phase-to-ground solid fault at $50 \%$ of cable's length.: (a) phase currents at Bus 11, (b) phase voltages at Bus 11, (c) current in HTS layer of phase A, (d) current in copper layer of phase A, (e) current in HTS layer of phase B, (f) current in copper layer of phase B, (g) current in HTS layer of phase $C,(\mathbf{h})$ current in copper layer of phase $C$.
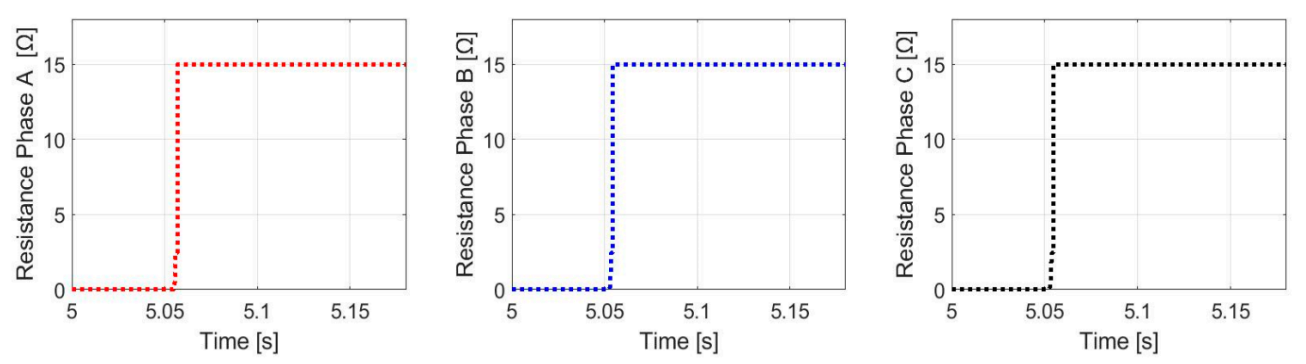

Figure 9. Equivalent resistance for phases A, B, and C for 3-Phase-to-ground solid fault at 50\% of cable's length.

Additionally, the fault currents, the voltage signatures, and the current distribution characteristics for a Phase-A-to-ground and a Phase-A-B-to-ground faults at the $50 \%$ of the HTS cable's length with $R_{f}=0.01 \Omega$ are reported in Figure 11 and Figure 12, respectively. The faulted phases of the proposed SCs have been found to behave in a similar way as in the previous case of the 3-Phase-to-ground fault. 
The characteristics of the superconductor resistance have the same trend as those presented in Figure 9 for the faulted phases. However, the equivalent resistance of the HTS layers of non-faulted phases remains at $0 \Omega$, as they do not quench and operate at superconducting state. Regarding the temperature rise for the faulted phases, it can be described based on Figure 10, while for the non-faulted phases the operating temperature remains constant at $70 \mathrm{~K}$ prior to and during the fault. For the non-faulted phases, the fault current flows only through the HTS layer. Therefore, the specific design target of the current limitation can be verified for different fault types with approximately zero fault resistance. Once the value of the fault current density exceeds the critical value $J_{C}(T)$ (Equation (11)) within the first fault cycle, the resistivity of the HTS layer increases based (refer to Equation (15)) and the fault current diverts to the copper stabilizer layer. The feasibility of the parallel stabilizer layer can been confirmed for 3-Phase-to-ground, Phase-A-to-ground and Phase-A-B-to-ground faults by observing the current distribution characteristics in Figure 8, Figure 11, and Figure 12 respectively. As the quenching process evolves, the temperature of the SCs increases, reaching values higher than the critical $T_{C}$; during the normal resistive mode, the value of the SCs equivalent resistance is only determined by the value of the stabilizer layer given by Equation (17). The further increase in temperature results in an increase in the resistivity of the copper stabilizer layer (Equation (17)) which leads to further reduction in fault current. The accuracy of the fault current limiting capability is verified by Figure 8 for a 3-Phase-to-ground fault, where the first peak of the fault current at $t=5.06 \mathrm{~s}$ is approximately $15 \mathrm{kA}$; however, within the first cycle, and before the fault clearance at $t=5.18 \mathrm{~s}$, the peak of the fault current is reduced to $1.8 \mathrm{kA}$. The same behaviour is observed for a Phase-A-to-ground and Phase-A-B-to-ground fault, as depicted by Figure 11 and Figure 12, respectively. The first peak of the fault current flowing through HTS layer, has values of $15 \mathrm{kA}$ for the faulted phases, while the resulted fault current flowing through the stabilizer layer has been limited to approximately $1.7 \mathrm{kA}$.
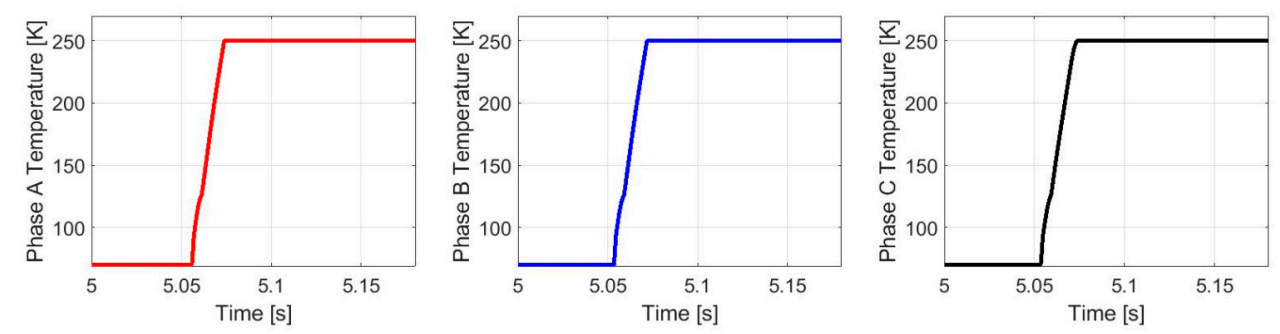

Figure 10. Temperature for phases A, B, and C for 3-Phase-to-ground fault at 50\% of cable's length.
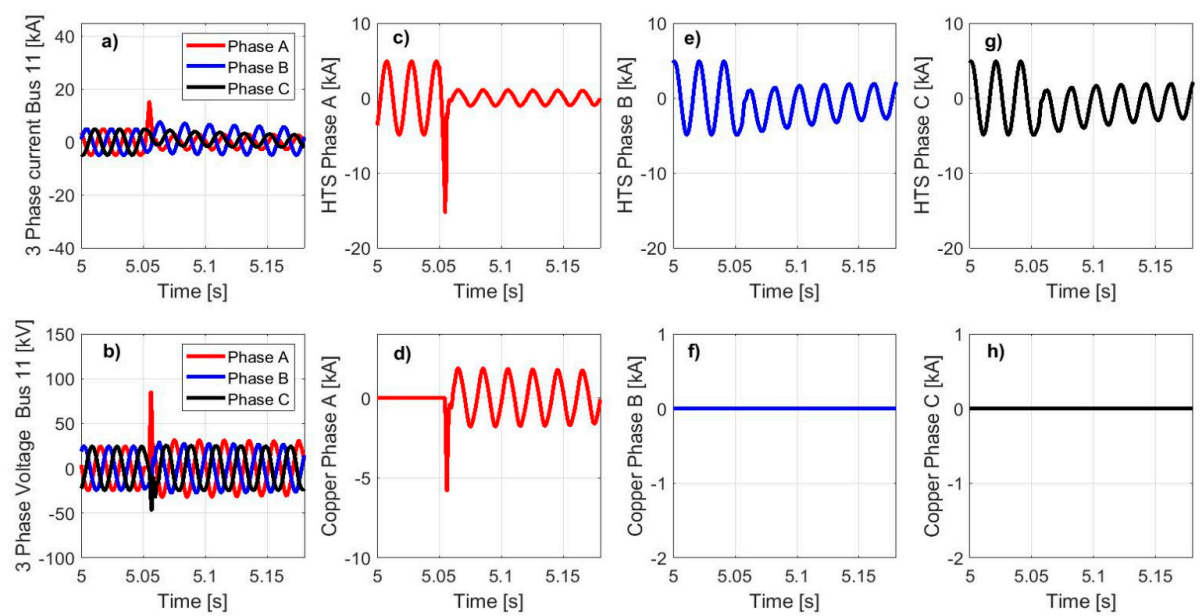

Figure 11. Fault current signatures for Phase-A-to-ground solid fault at $50 \%$ of cable's length: (a) phase currents at Bus 11, (b) phase voltages at Bus 11, (c) current in HTS layer of phase A, (d) current in copper layer of phase A, (e) current in HTS layer of phase B, (f) current in copper layer of phase B, (g) current in HTS layer of phase C, (h) current in copper layer of phase C. 

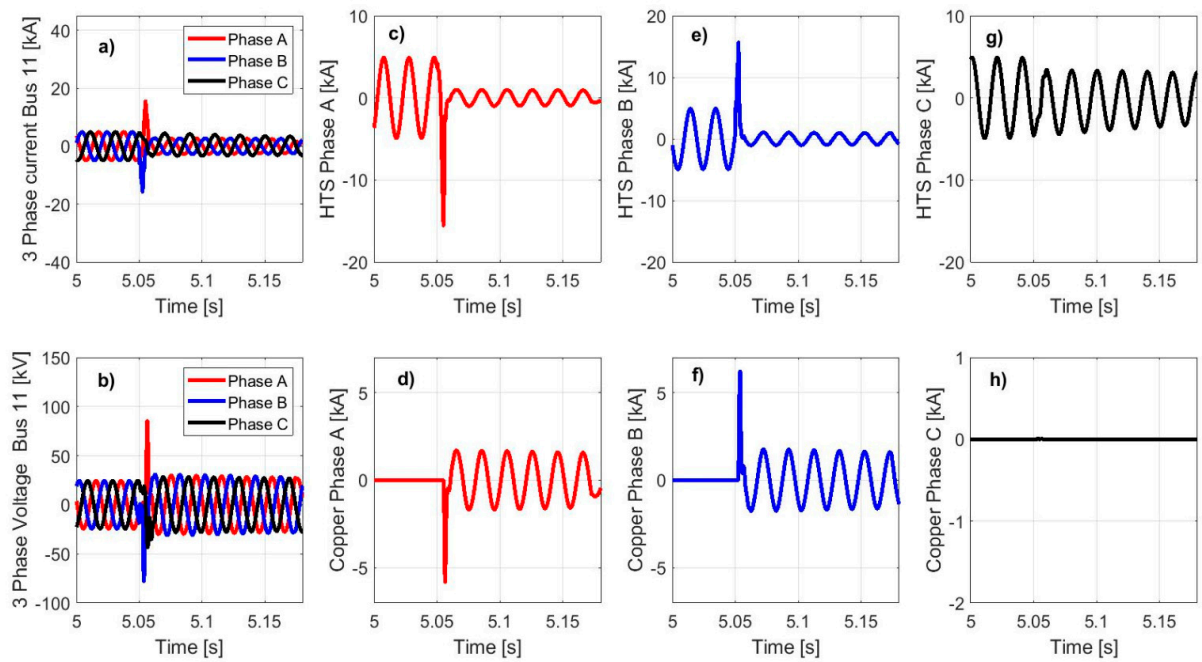

Figure 12. Fault current signatures for Phase-A-to-ground Phase-A-B-to-ground solid fault at $50 \%$ of cable's length: (a) phase currents at Bus 11, (b) phase voltages at Bus 11, (c) current in HTS layer of phase A, (d) current in copper layer of phase A, (e) current in HTS layer of phase B, (f) current in copper layer of phase B, (g) current in HTS layer of phase $C,(\mathbf{h})$ current in copper layer of phase C.

\subsection{Current Limitation}

In this Section, the presented analysis aims to evaluate the transient performance of the SCs in contrast with a conventional copper cable installed at the same power system. For this reason, emphasis has been given on the calculation of the current-limitation capability as a percentage of the prospective fault current flowing through a conventional copper cable, during the quenching process. In particular, a 3-Phase-to-ground fault with fault resistance of $R_{f}=0.01 \Omega$ was applied at the $50 \%$ of the SCs length. The same fault has been repeated for the case of conventional copper cable. The fault currents captured by the SCs model during the simulations have been compared with the prospective fault currents through the conventional copper cable, highlighting the merits arising by utilizing superconductors. Figure 13 demonstrates the RMS value of the fault currents at Bus 11 during a 6-cycle 3-Phase-to-ground fault for both cases.
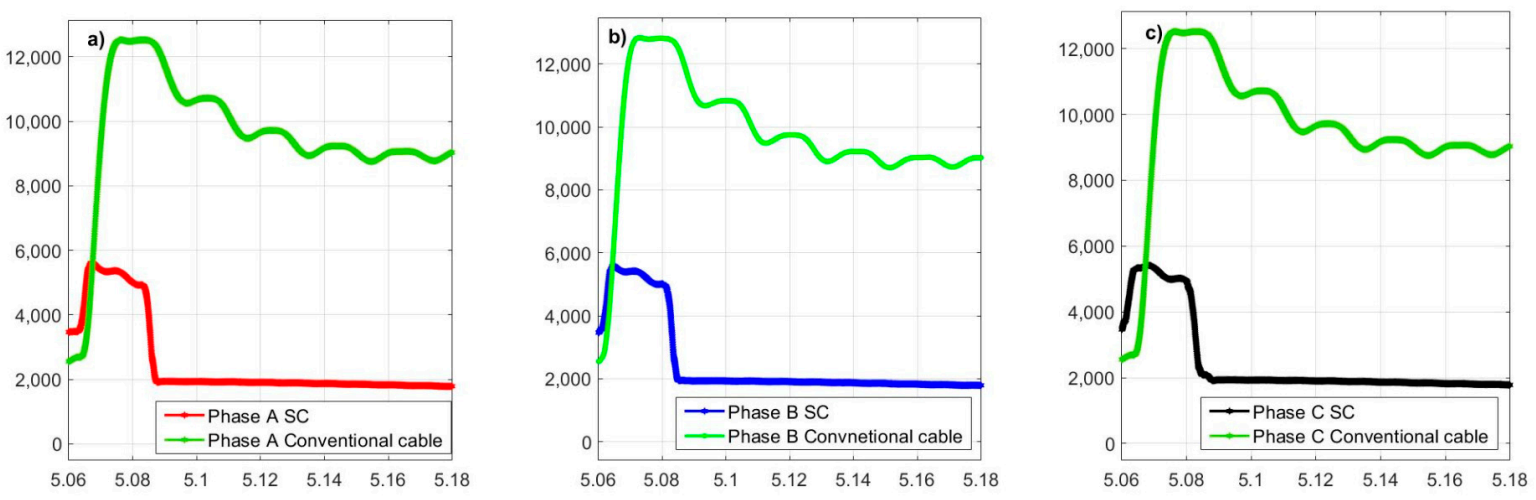

Figure 13. RMS values of the fault currents at Bus 11 during 3-Phase-to-ground solid fault at $50 \%$ of the proposed SCs and a conventional copper cable: (a) Phase A, (b) Phase B, (c) Phase C.

Similarly, to the previous Section, the fault is initiated at $t=5.06 \mathrm{~s}$ and cleared after $120 \mathrm{~ms}$. When the fault occurs at $t=5.06 \mathrm{~s}$, the RMS value of the current for the SCs is slightly higher compared to that of the conventional cable, as at the initial quenching state (stage 2) the resistance of the HTS tapes has not reached high values yet. It is well-established that the short-circuit magnitude is determined by the $\mathrm{X} / \mathrm{R}$ ratio of the circuit. Therefore, it can be seen that the RMS values of the fault currents 
start to decrease at the time instant of $t=5.065 \mathrm{~s}$, due to the high resistance and the significant temperature increase.

To quantify the fault current limitation by adding the fault current limiting function, a current limitation percentage of the prospective current through a conventional cable has been introduced based on Equation (30). Particularly, for the case of the SCs the RMS values of the limited fault currents during the whole quenching process (stage 2 and stage 3 ) have been calculated and compared with the prospective current values. Figure 14 shows the current limitation percentage per phase, verifying and supporting the practical feasibility of the proposed cable design,

$$
I_{\text {current-limitation }}(\%)=\frac{I_{\text {conv }}-I_{S C}}{I_{\text {conv }}} \cdot(100 \%)
$$

where $I_{\text {conv }}$ is the RMS value of the fault current flowing through the conventional copper cable and $I_{S C}$ is the fault current flowing through the SCs under the same type of fault. The current limitation presents a slight difference among phases due to the difference in phase angle of each phase at the fault instant.

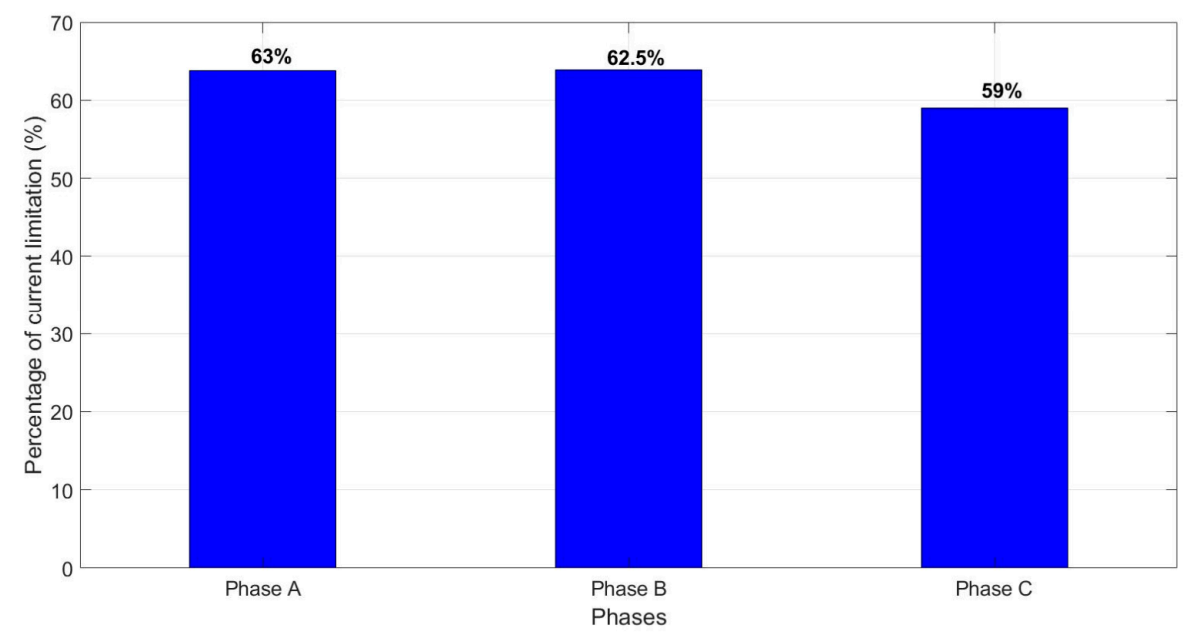

Figure 14. Current limitation percentage (\%) of the SCs for phases A, B, and C compared to a conventional copper cable during a 3-Phase-to-ground fault at $50 \%$ of cable's length.

It is evident that the installation of SCs can lead to fault current reduction up to $62.5 \%$ of the prospective current flowing through a conventional copper cable, considering the same 3-Phase-to-ground fault.

\subsection{Simulation Analysis of Fault Resistance Effect on the Quenching Process}

In order to achieve the maximum benefit of the designed cable, its performance under a wide range of power system conditions should be comprehensively evaluated. In the available technical literature, several studies [45-50] have investigated the impact of the fault resistance $R_{f}$ on the superconducting current limiters. However, there are no studies available assessing the impact of the fault resistance on the SCs and the fault current limitation that it provides. Therefore, in this Section the quenching process of the SCs is analyzed in accordance with the gradual increase in the fault resistance value. Simulation studies, which include 3-Phase-to-ground faults applied at the $50 \%$ of SCs length (considering different values of $R_{f}$ ), were conducted to study the relationship between $R_{f}$ and the quenching process. Figures 15-20 show the corresponding waveforms of the quenching stage, the fault current signatures among the layers, the resistance and the temperature of the cable for $R_{f 1}=1 \Omega, R_{f 2}=5 \Omega$ and $R_{f 3}=10 \Omega$, respectively. 

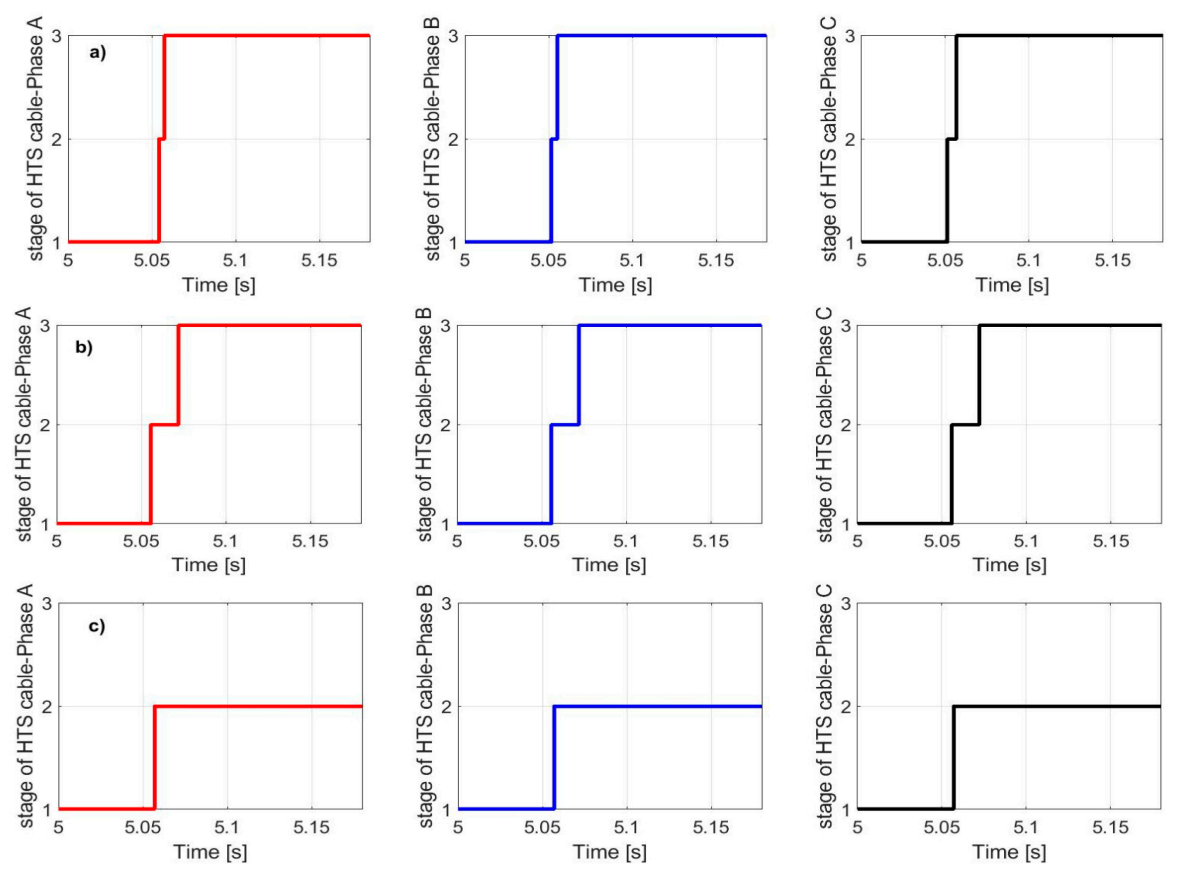

Figure 15. Stages of quenching process for phase A, B, and C for 3-Phase-to-ground fault at $50 \%$ of cable's length with (a) $R_{f 1}=1 \Omega$, (b) $R_{f 2}=5 \Omega$, (c) $R_{f 3}=10 \Omega$.

Based on the results depicted in Figure 16, when fault resistance is $R_{f 1}=1 \Omega$, the HTS tapes quench at the first half fault cycle and enter normal state (stage 3), as it can be seen in Figure 15a. The resistance and the temperature reach their maximum values at $t=5.065 \mathrm{~s}$, as shown in Figures 19a and 20a, respectively. Therefore, the current starts to flow through the stabilizer layer at $t=5.065 \mathrm{~s}$, $5 \mathrm{~ms}$ after the fault occurs. For the case of $R_{f 2}=5 \Omega$, HTS tapes quench after one fault cycle (at $t=5.082 \mathrm{~s}$ ) and it is noticeable by Figure 15b that stage 2 lasts for a slightly longer period (few $\mathrm{ms}$ ). Considering a fault resistance of $R_{f 1}=1 \Omega$, SCs operate within stage 2 for $5.5 \mathrm{~ms}$, while, for $R_{f 2}=5 \Omega$, stage 2 lasts for $18 \mathrm{~ms}$. Furthermore, for fault resistance $R_{f 2}=5 \Omega$, the first fault current peaks depicted in Figure 18c,e,g are lower compared to the fault current peaks extracted during the fault with $R_{f 1}=1 \Omega$, as a larger value of fault resistance results in lower fault currents. Regarding the case of $R_{f 3}=10 \Omega$, the HTS tapes of the faulted phases quench, reaching only stage 2 , without entering into normal state. Therefore, the maximum value of the SCs equivalent resistance is low, $R_{e q}=0.058 \Omega$ and the fault currents flow through the HTS layers. This behaviour indicates that the increase in the fault resistance value affects the quenching degree and consequently the current sharing between the HTS and stabilizer layers. Particularly, as it has already been analyzed (also reported in [28]), temperature increase plays a key role in the resulting value of the equivalent resistance and the quenching degree, which in turn is determined by the generated resistive heat, the magnitude, and the duration of the fault current. By observing, Figure 20a, it is obvious that for a 3-Phase-to-ground fault with $R_{f 1}=1 \Omega$, the temperature of the superconductor exceeds the critical value $T_{C}$, reaching the maximum value of $250 \mathrm{~K}$. When a 3-Phase-to-ground fault with $R_{f 2}=5 \Omega$ occurs, the temperature exceeds the critical value $T_{C}=92 \mathrm{~K}$, but it is noticeable from Figure 20b, that the temperature reaches the maximum value of $250 \mathrm{~K}$ with a delay, which affects the quenching process. In the last case of $R_{f 3}=10 \Omega$, the boundary condition $I_{\text {fault }}>I_{C}$ of quenching has been met. Although the temperature does not reach the critical value $T_{C}$, resulting in "incomplete quenching". The resistance of the HTS tapes reach low values, affecting the value of the equivalent resistance and the current distribution among the layers and resulting in small percentage of fault current limitation. The fault current flows mainly through the HTS layers. 

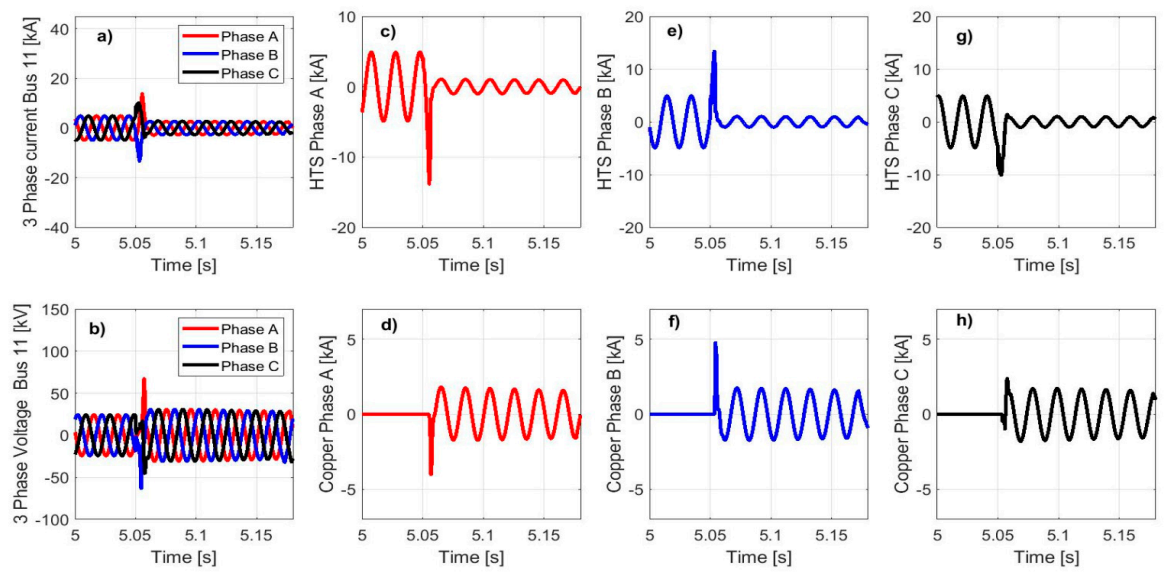

Figure 16. Fault current signatures for 3-Phase-to-ground fault at $50 \%$ of cable's length: with $R_{f 1}=1 \Omega$ (a) phase currents at Bus 11, (b) phase voltages at Bus 11, (c) current in HTS layer of phase A, (d) current in copper layer of phase A, (e) current in HTS layer of phase B, (f) current in copper layer of phase B, (g) current in HTS layer of phase C, (h) current in copper slayer of phase C.

The results revealed that the fault resistance has a considerable impact on the SCs performance for the same type of fault, considering the same fault location. For instance, further increase in the fault resistance can lead to much lower fault currents, even below the critical current $I_{C}$, preventing SCs from quenching. This has been confirmed by Figure 18, where, during a 3-Phase-to-ground fault with $R_{f 3}=10 \Omega$, the first peak of the fault current is below the critical current $I_{C}$, and therefore there is no quenching or fault current sharing between the two layers. Consequently, low values of fault resistance result in higher fault current (with respect to the critical current $I_{C}$ ), which lead to SCs quenching during the first half cycle, and therefore to greater fault current limitation capability (Figure 16). High fault resistance affects the quenching degree and jeopardizes the fault current limiting capability of the cable. This can be explained by the reduced allocation of fault current within different layers during current limitation mode, as fault current is predominately limited by the fault resistance value.
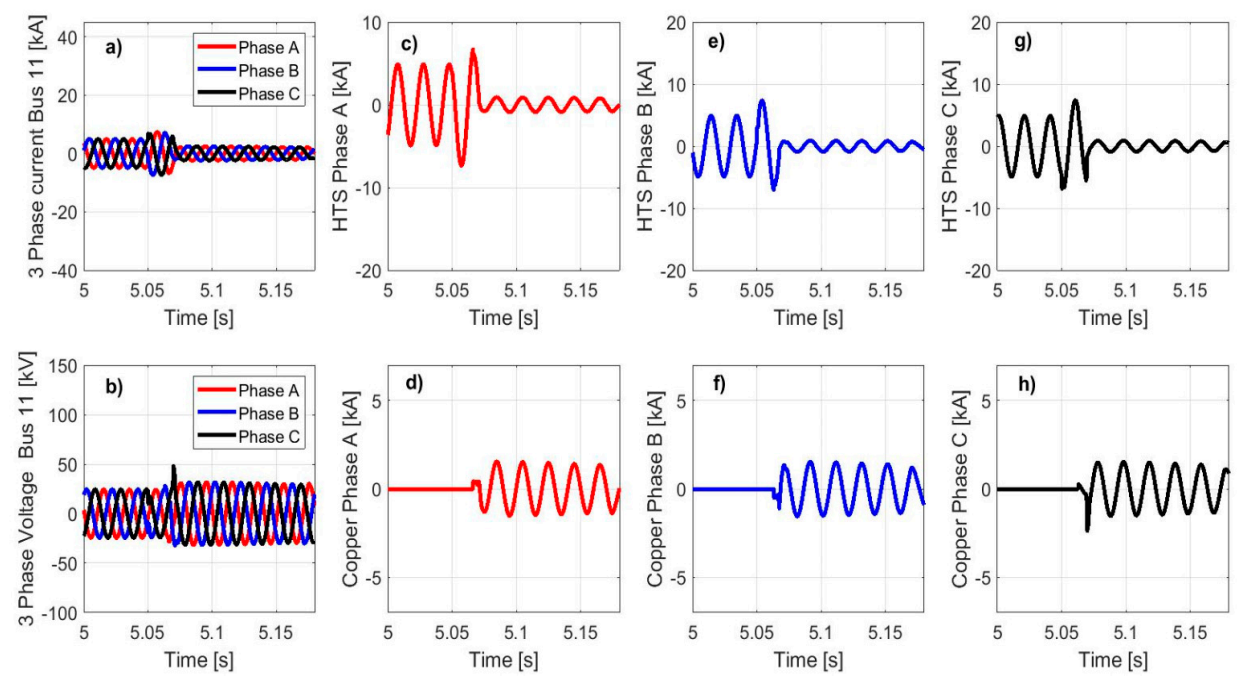

Figure 17. Fault current signatures for 3-Phase-to-ground fault at $50 \%$ of cable's length: with $R_{f 2}=5 \Omega$ (a) phase currents at Bus 11, (b) phase voltages at Bus 11, (c) current in HTS layer of phase A, (d) current in copper layer of phase A, (e) current in HTS layer of phase B, (f) current in copper layer of phase B, (g) current in HTS layer of phase C, (h) current in copper slayer of phase C. 

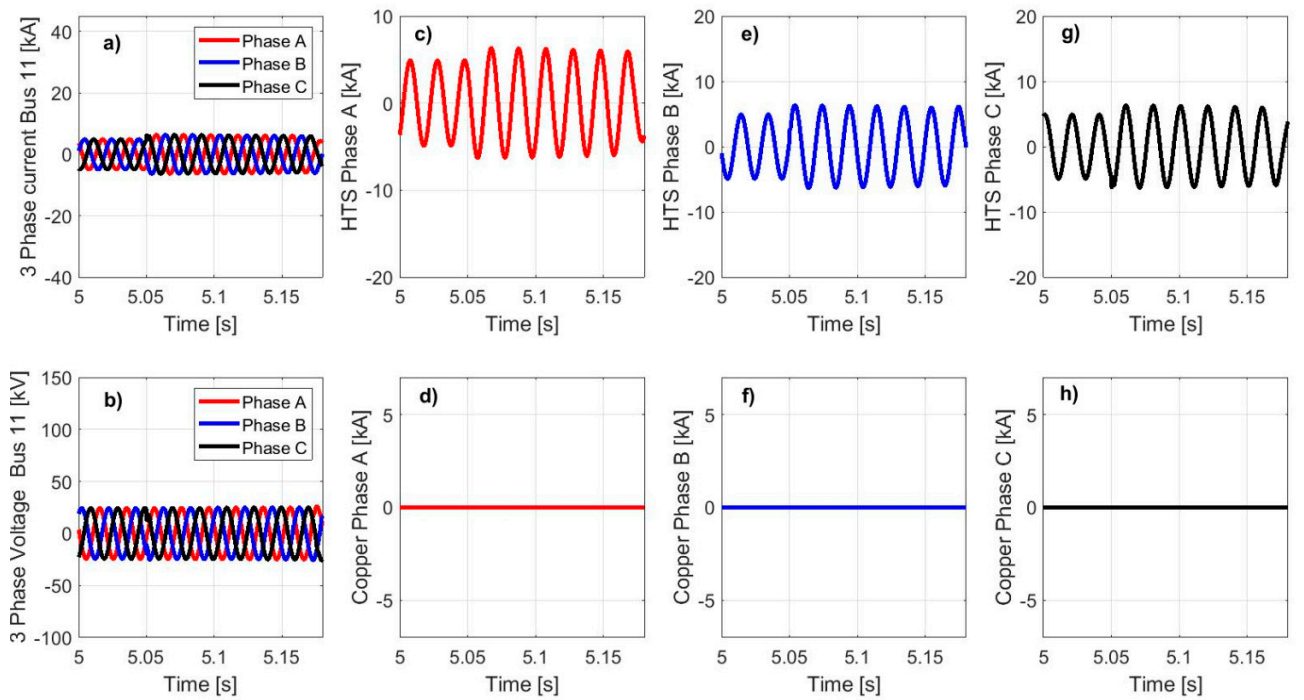

Figure 18. Fault current signatures for 3-Phase-to-ground fault at $50 \%$ of cable's length: with $R_{f 3}=10 \Omega$ (a) phase currents at Bus 11, (b) phase voltages at Bus 11, (c) current in HTS layer of phase A, (d) current in copper layer of phase A, (e) current in HTS layer of phase B, (f) current in copper layer of phase B, (g) current in HTS layer of phase C, (h) current in copper slayer of phase C.
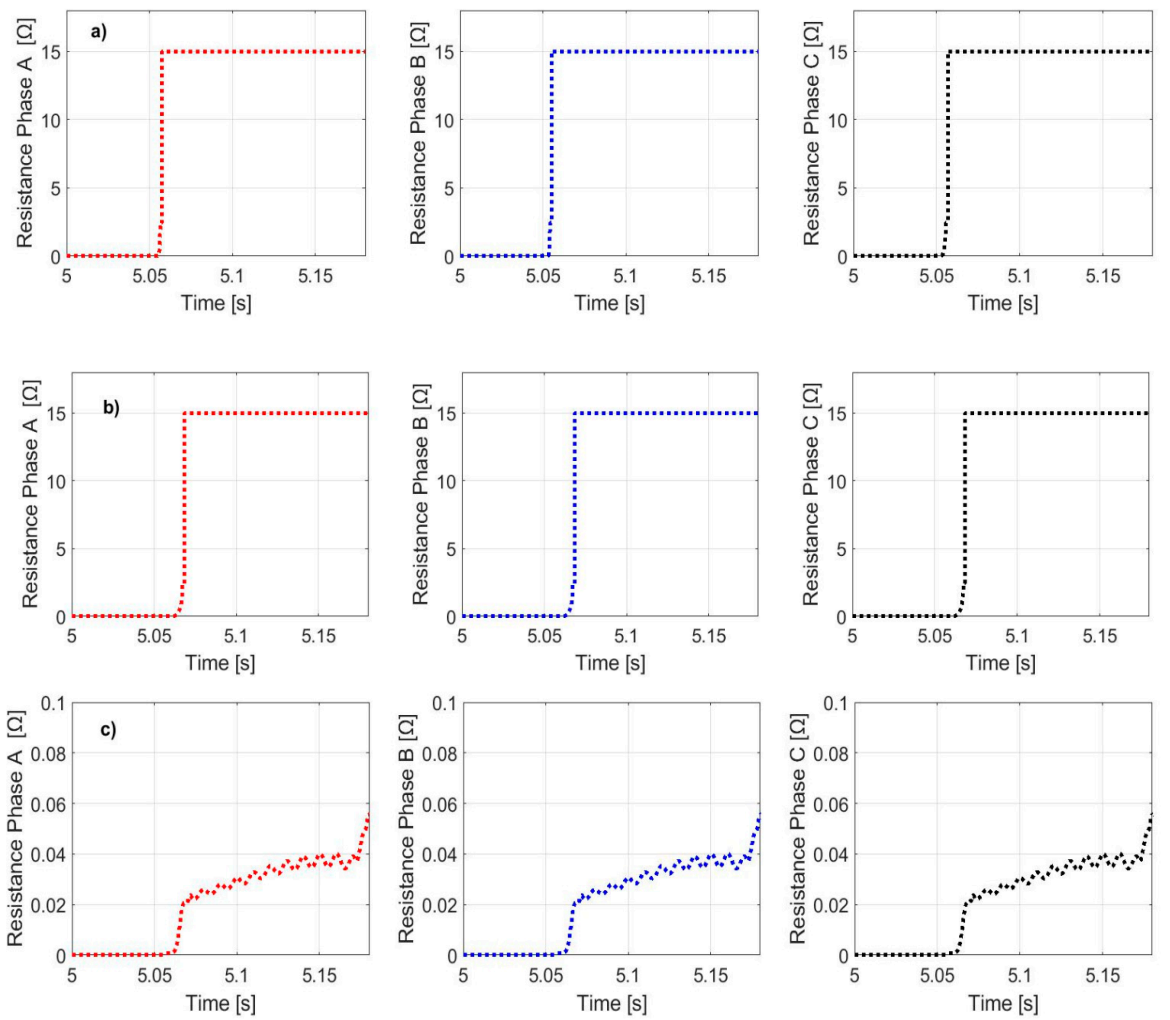

Figure 19. Equivalent resistance for phases $A, B$, and $C$ for 3-Phase-to-ground fault at $50 \%$ of cable's length, with: (a) $R_{f 1}=1 \Omega$, (b) $R_{f 2}=5 \Omega$, (c) $R_{f 3}=10 \Omega$. 

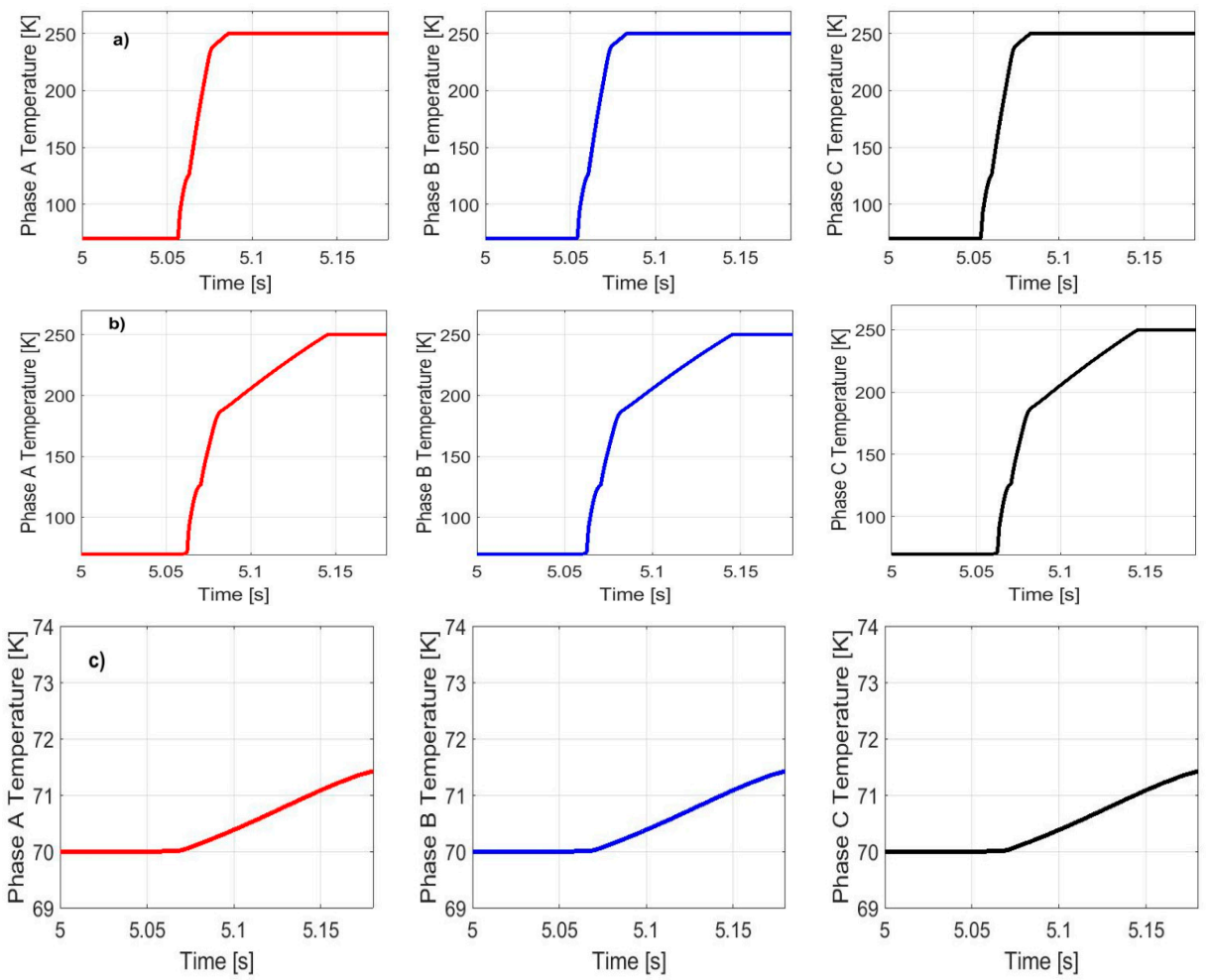

Figure 20. Temperature for phases A, B, and C for 3-Phase-to-ground fault at 50\% of cable's length, with: (a) $R_{f 1}=1 \Omega$ (b) $R_{f 2}=5 \Omega$ (c) $R_{f 3}=10 \Omega$.

\section{Conclusions and Verifications}

The comprehensive fault current characterization presented in this paper used a simplified, validated SCs model and highlighted the following key outcomes:

The operation of the SCs can be divided into three different stages: (i) the superconducting stage during the steady state operation of a power system, at which the SCs presents approximately zero resistance; (ii) the quenching process, which includes the partial resistive flux flow stage, reached when the fault current exceeds the critical current $I_{C}$ and while temperature remains below the critical value $T_{C}$; and (iii) the highly resistive normal state which is reached once the temperature exceeds the critical value $T_{C}$. Furthermore, it has been found that during fault, the stabilizer layer can be used as a parallel path for the transient current, reducing heat generation, temperature rise, and protecting the cable from being damaged. To better investigate the feasibility of the copper stabilizer layer, the change of the copper layer resistivity has been modelled during the normal resistive mode, while the resistance of the HTS layer considered to be constant (i.e., set to its maximum value).

The performance of the SCs in limiting the fault currents was assessed through a number of fault scenarios. Simulation results revealed the impact of SCs on fault current magnitudes, under different type of faults, and as a consequent on the short-circuit level of the power systems. Specifically, it has been observed that within the first electric cycle, the magnitude of the fault current has been reduced from $15 \mathrm{kA}$ to approximately $1.8 \mathrm{kA}$. Therefore, the installation of SCs introduces a challenge for the existing protection schemes due to their variable resistance, which leads to lower fault currents and higher voltage magnitude during transient conditions. In order to obtain a deeper insight of the fault current limiting capability of SCs, a comparative analysis has been conducted between the SCs and a conventional copper cable under the same fault conditions. The analysis revealed that for 3-Phase-to-g faults, the SCs model offers fault current limitation in the range of $60 \%$, with respect to the prospective values. Therefore, the deployment of SCs increases the transmission efficiency due to the low resistance during the steady state and suppresses fault currents. The obtained results are well-aligned with relevant conducted studies such as $[19,36,40]$. 
The performance of SCs during transient conditions is determined by certain power system characteristics such as the prospective fault currents and fault resistance. In particular, simulation results showed that the increase in the fault resistance value impacts on the feasibility of the SCs, as it affects the quenching degree. It was revealed that the higher the fault resistance, the lower the prospective current and the percentage of current limitation. This was confirmed through the case of fault resistance equal to $R_{f 3}=10 \Omega$, where the fault current is predominately limited by the fault resistance, affecting the increase in the resistivity of HTS tapes (which do not enter normal state) and the quenching process.

\section{Future Work}

After the fault current characterization and evaluation of SCs' performance during fault conditions, it has been identified that that there are many challenges that the protection schemes must take into consideration. As the simulation results revealed, the variable resistance of SCs, the reduced fault currents, the higher voltage magnitude during quenching stages, and the impact of high fault resistance values which jeopardize the quenching process, are factors which are anticipated to introduce challenges to the fault detection and classification methods, and by extension to the applicability of conventional protection schemes (e.g., over-current, distance protection, etc.) towards protecting SCs feeders. Considering the protection of future power grids (integrating SCs and inverter-connected generation), more research shall be steered towards the development of novel protection solutions which capture the particularities and distinctive features of SCs. For example, potential merits can arise from the utilization of learning-based methods for fault diagnosis on SCs, such as Deep-Learning techniques, which take advantage of the sequential relationships of the data and are able to handle long-term dependencies and correlated features that are important for fault diagnosis.

Author Contributions: Conceptualization and Investigation, E.T., A.E. and D.T.; Methodology E.T., D.T., A.E., A.D. and M.E.; Resources E.T., A.E., Q.H., W.Y. and M.E.; Software E.T., A.E. and D.T.; Analyses and interpretation of data E.T., A.E., D.T., W.Y. and A.D.; Supervision D.T., A.D., C.B. and Q.H.; Visualization E.T.; Writing-original draft E.T.; Writing-review and editing D.T., A.E., A.D., C.B., Q.H., M.E. and W.Y. All authors have read and agreed to the published version of the manuscript.

Funding: This research received no external funding.

Conflicts of Interest: The authors declare no conflict of interest.

\section{References}

1. Zhang, Z.; Venuturumilli, S.; Zhang, M.; Yuan, W. Superconducting cables-Network feasibility study work package 1. In Innovation, Next Generation Networks; Western Power Distribution: Castle Donington, UK, 2016; Volume 9, pp. 8-15.

2. Blair, S.M.; Booth, C.D.; Burt, G.M. Current-Time Characteristics of Resistive Superconducting Fault Current Limiters. IEEE Trans. Appl. Supercond. 2012, 22, 5600205. [CrossRef]

3. Blair, S.M.; Booth, C.D.; Elders, I.M.; Singh, K.N.; Burt, G.M.; McCarthy, J. Suprconducting fault current limiter application in power dense marine electrical system. IET Elect. Sust. Transp. 2011, 1, $93-102$. [CrossRef]

4. Blair, S.M.; Singh, N.K.; Booth, C.D. Operational control and protection implications of fault current limitation in distribution networks. In Proceedings of the 2009 44th International Universities Power Engineering Conference (UPEC), Glasgow, UK, 1-4 September 2009; pp. 1-5.

5. Albany Power Cables. Available online: https://www.energy.gov/sites/prod/files/oeprod/DocumentsandMedia/ Albany_03_05_08.pdf (accessed on 6 June 2020).

6. Kojima, H.; Kotari, M.; Kito, T.; Hayakawa, N.; Hanai, M.; Okubo, H. Current Limiting and Recovery Characteristics of 2 MVA Class Superconducting Fault Current Limiting Transformer (SFCLT). IEEE Trans. Appl. Supercond. 2010, 21, 1401-1404. [CrossRef] 
7. Liang, F.; Yuan, W.; Baldan, C.A.; Zhang, M.; Lamas, J.S. Modeling and Experiment of the Current Limiting Performance of a Resistive Superconducting Fault Current Limiter in the Experimental System. J. Supercond. Nov. Magn. 2015, 28, 2669-2681. [CrossRef]

8. Stuart, W.; Strickland, N. Critical Current Characterization of THEVA Production 2G HTS Superconducting Wire. Available online: https://figshare.com/articles/dataset/Critical_current_characterisation_of_THEVA_ pre-oduction_2G_HTS_superconducting_wire/375932 (accessed on 7 June 2020).

9. Mark, F.M. Ampacity Project-Worldwide First Superconducting Cable and Fault Current Limiter intallation in a German City center. In Proceedings of the 22nd International Conference on Electricity Distribution, Stockholm, Sweden, 10-13 June 2013.

10. Shibata, T.; Watanabè, M.; Suzawa, C.; Isojima, S.; Fujikami, J.; Sato, K.; Ishii, H.; Honjo, S.; Iwata, Y. Development of high temperature superconducting power cable prototype system. IEEE Trans. Power Deliv. 1999, 14, 182-187. [CrossRef]

11. Sohn, S.; Lim, J.; Yang, B.; Lee, S.; Jang, H.; Kim, Y.; Yang, H.; Kim, D.; Kim, H.; Yim, S.; et al. Design and development of 500m long HTS cable system in the KEPCO power grid, Korea. Phys. C Supercond. 2010, 470, 1567-1571. [CrossRef]

12. Ballarino, A.; Bruzek, C.E.; Dittmar, N.; Giannelli, S.; Goldacker, W.; Grasso, G.; Grilli, F.; Haberstroh, C.; Hole, S.; Lesur, F.; et al. The BEST PATHS Project on MgB2Superconducting Cables for Very High Power Transmission. IEEE Trans. Appl. Supercond. 2016, 26, 1-6. [CrossRef]

13. Kalsi, S.S. HTS Superconductors. Appl. High Temperarure Supercond. Electr. Power Equip. 2011, 9, $219-259$.

14. Muncho, J.M. Development trend of Superconducting Cable Technology for Power Transmission Applications. World Congr. Eng. Comput. 2015, 1, 1-4.

15. Snitcher, G.; Kalsi, S.S.; Manlief, M.; Schwall, E.E.; Sidi-Yekhief, A.; Ige, S.; Francavilla, T.L.; Gusber, D.U. High-filed warm-bore HTS conduction cooled magnet. IEEE Trans. Appl. Supercond. 1999, 9, 553-558. [CrossRef]

16. Luiz, A. Applications of High-Tc Superconductivity; IntechOpen: Rijeka, Croatia, 2011; Volume 3, pp. 46-72.

17. Akhtar, M.J. 100 Years of Superconductivity (1911-2011). Nuclues 2011, 48, 261.

18. Huebener, R.R. Conductors, Semiconductors, Superconductors: An introduction tosolid state physics. Univ. Tub. 2004, 3, 120-141.

19. Young, M.A. An investigation of the current distribution in the trixial cable and its operational impacts on power systems. IEEE Trans. Appl. Supercond. 2005, 15, 1751-1754. [CrossRef]

20. Bang, J. Critical current, criticial temperature anf magnetic filed based EMTDC model components for HTS power cables. IEEE Trnas. Appl. Supercond. 2007, 17, 1726-1729. [CrossRef]

21. Yoon, D.-H. A Feasibility Study on HTS Cable for the Grid Integration of Renewable Energy. Phys. Procedia 2013, 45, 281-284. [CrossRef]

22. Malozemoff, A.P. High Temperature Seperconducting HTS AC Cables for Power Grid Applications. In Superconductors in Power Grid; Woodhead Publishing: Sawston, UK, 2015; pp. 133-188.

23. Jipping, J.; Mansoldo, A.; Wakefield, C. The impact of HTS cables on power flow distribution and short-circuit currents within a meshed network. In Proceedings of the 2001 IEEE/PES Transmission and Distribution Conference and Exposition, Developing New Perspectives (Cat. No.01CH37294), Atlanta, GA, USA, 2 November 2002; pp. 736-741. [CrossRef]

24. Maruyama, O.; Nakano, T.; Mimura, T.; Morimura, T.; Masuda, T.; Takagi, T.; Yagi, M. Fundamental Study of Ground Fault Accident in HTS Cable. IEEE Trans. Appl. Supercond. 2017, 27, 1-5. [CrossRef]

25. Ishiyama, A.; Wang, X.; Ueda, H.; Uryu, T.; Yagi, M.; Fujiwara, N. Over-Current Characteristics of 275-kV Class YBCO Power Cable. IEEE Trans. Appl. Supercond. 2010, 21, 1017-1020. [CrossRef]

26. Maguire, J.; Folts, D.; Yuan, J.; Henderson, N.; Lindsay, D.; Knoll, D.; Rey, C.; Duckworth, R.; Gouge, M.; Wolff, Z.; et al. Status and progress of a fault current limiting hts cable to be installed in the con edison grid. AIP Conf. Proc. 2010, 1218, 445.

27. Maguire, J.; Folts, D.; Yuan, J.; Lindsay, D.; Knoll, D.; Bratt, S.; Wolff, Z.; Kurtz, S. Development and Demonstration of a Fault Current Limiting HTS Cable to be Installed in the Con Edison Grid. IEEE Trans. Appl. Supercond. 2009, 19, 1740-1743. [CrossRef] 
28. Liang, S.; Ren, L.; Ma, T. Study on quenching characteristics and resistance equievalent estimation method of second-generation High Temperature Superconducting tape under different overcurrent. Materials 2019, 12, 2374. [CrossRef]

29. Doukas, D.I.; Chrysochos, A.I.; Labridis, D.P.; Harnefors, L.; Velotto, G. Coupled electro-mechanical transient analysis of superconducting DC transmission system using FDTD and VEM modelling. IEEE Trans. Appl. Supercond. 2017, 27, 1-8. [CrossRef]

30. Fukui, S.; Ogawa, J.; Suzuki, N.; Oka, T.; Sato, T.; Tsukamoto, O.; Takao, T. Numerical Analysis of AC Loss Characteristics of Multi-Layer HTS Cable Assembled by Coated Conductors. IEEE Trans. Appl. Supercond. 2009, 19, 1714-1717. [CrossRef]

31. Yao, M. Numerical Modelling of Superconducting Power Cables with Second Generation High Temperature Superconductors. Ph.D. Thesis, University of Edinburgh, Scotland, UK, 2019.

32. Su, R.; Shi, J.; Yan, S.; Li, P.; Wng, W.; Hu, Z.; Zhang, B.; Tnag, Y.; Ren, L. Numerical model of HTS cable and its electri-thermal properties. IEEE Trans. Appl. Supercond. 2019, 29, 1-5.

33. Shaghai Superconductors. Available online: http://www.shsctec.com/en/introduce/89 (accessed on 10 June 2020).

34. Polak, M.; Krempaský, L.; Chromik, Š.; Wehler, D.; Moenter, B. Magnetic field in the vicinity of YBCO thin film strip and strip with filamentary structure. Phys. C Supercond. 2002, 372, 1830-1834. [CrossRef]

35. Du, H.-I.; Kim, T.-M.; Han, B.-S.; Hong, G.-H. Study on Verification for the Realizing Possibility of the Fault-Current-Limiting-Type HTS Cable Using Resistance Relation With Cable Former and Superconducting Wire. IEEE Trans. Appl. Supercond. 2015, 25, 1-5. [CrossRef]

36. Nguyen, T.-T.; Lee, W.-G.; Lee, S.-J.; Park, M.; Kim, H.-M.; Won, D.; Yoo, J.; Yang, H.S. A Simplified Model of Coaxial, Multilayer High-Temperature Superconducting Power Cables with $\mathrm{Cu}$ Formers for Transient Studies. Energies 2019, 12, 1514. [CrossRef]

37. Choi, Y.; Kim, J.; Kim, Y.; Ko, T.; Lee, H.; Kim, J.; Choi, Y. Quench and recovery characteristics of second-generation high-temperature superconducting GdBCO coated conductor with various patterns of stabilizers. Results Phys. 2018, 10, 222-226. [CrossRef]

38. Fu, Y.; Tsukamoto, O.; Furuse, M. Copper stabilization of YBCO coated conductor for quench protectio. IEEE Trans. Appl. Supercond. 2003, 13, 1780-1783. [CrossRef]

39. Zhu, J.; Zhang, Z.; Zhang, M.; Zhang, M.; Qiu, M.; Yuan, W. Electric Measurement of the Critical Current, AC Loss, and Current Distribution of a Prototype HTS Cable. IEEE Trans. Appl. Supercond. 2013, 24, 1-4. [CrossRef]

40. Elshiekh, M.; Zhang, M.; Ravindra, H.; Chen, X.; Venuturumilli, S.; Huang, X.; Schoder, K.; Steurer, M.; Yuan, W. Effectiveness of Superconducting Fault Current Limiting Transformers in Power Systems. IEEE Trans. Appl. Supercond. 2018, 28, 1-7. [CrossRef]

41. Torii, S.; Kasahara, H.; Akita, S. Temperature dependence of critical current density of AC superconductor and the effect on AC quench current degradation. IEEE Trans. Appl. Supercond. 1995, 5, 369-372. [CrossRef]

42. Hong, Z.; Campbell, A.M.A.; Coombs, T. Numerical solution of critical state in superconductivity by finite element software. Supercond. Sci. Technol. 2006, 19, 1246-1252. [CrossRef]

43. Serway, R.A.; Kirkpatrick, L.D. Physics for Scientists and Engineers with Modern Physics. Phys. Teach. 1988, 26, 254-255. [CrossRef]

44. Jin, T.; Hong, J.-P.; Zheng, H.; Tang, K.; Gan, Z.-H. Measurement of boiling heat transfer coefficient in liquid nitrogen bath by inverse heat conduction method. J. Zhejiang Univ. A 2009, 10, 691-696. [CrossRef]

45. Colombus HTS Cables. Available online: https://www.energy.gov/sites/prod/files/oeprod/DocumentsandMedia/ columbus_03.05.08.pdf (accessed on 7 June 2020).

46. Barzegar-Bafrooei, M.R.; Foroud, A.A. Impact of fault resistance and fault distance on fault current reduction ratio of hybrid SFCL. Int. Trans. Electr. Energy Syst. 2017, 27, e2409. [CrossRef]

47. Mansour, D.-E.A. Effect of fault resistance on the behavior of superconducting fault current limiter in power systems. In Proceedings of the 2014 IEEE International Conference on Power and Energy (PECon), Kuching, Malaysia, 1-3 December 2014; pp. 212-216. [CrossRef]

48. Kalsi, S.S. Applications of High Temperature Superconductors to Electric Power Equipment; John Wiley \& Sons: Hoboken, NJ, USA, 2011; pp. 173-217. [CrossRef] 
49. Xie, Y.-Y.; Tekletsadik, K.; Hazelton, D.; Selvamanickam, V. Second Generation High-Temperature Superconducting Wires for Fault Current Limiter Applications. IEEE Trans. Appl. Supercond. 2007, 17, 1981-1985. [CrossRef]

50. Lin, B.; Ying, L.; Sheng, J.; Zhang, J.; Yao, L.; Li, Y.; Jin, Z.; Hong, Z. Test of Maximum Endurable Quenching Voltage of YBCO-Coated Conductors for Resistive Superconducting Fault Current Limiter. IEEE Trans. Appl. Supercond. 2011, 22, 5602904. [CrossRef]

Publisher's Note: MDPI stays neutral with regard to jurisdictional claims in published maps and institutional affiliations.

(C) 2020 by the authors. Licensee MDPI, Basel, Switzerland. This article is an open access article distributed under the terms and conditions of the Creative Commons Attribution (CC BY) license (http://creativecommons.org/licenses/by/4.0/). 